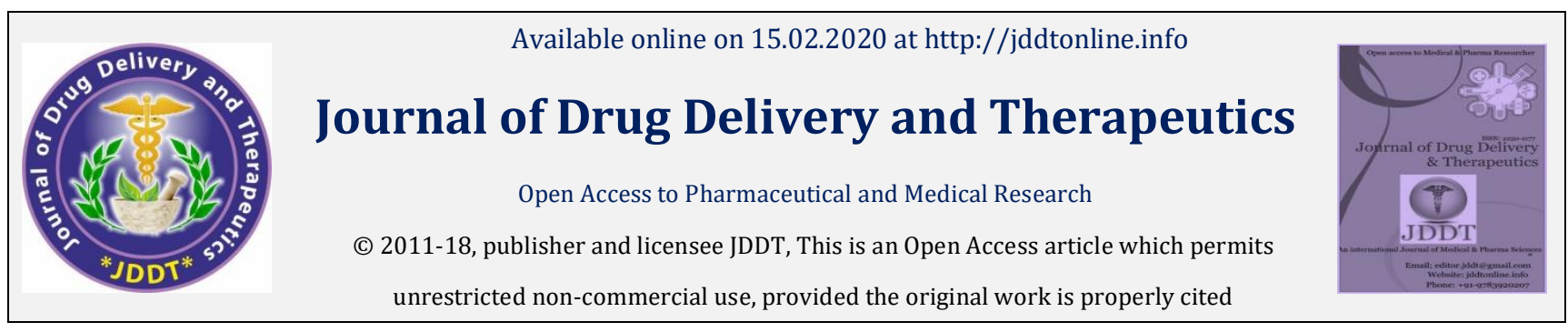

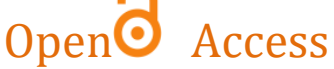

\section{Glyphosate and Non-Hodgkin lymphoma: No causal relationship}

\author{
Ilija Barukčić \\ Internist, Horandstrasse, DE-26441 Jever, Germany
}

\begin{abstract}
Objective: Herbicides are used worldwide by both residential and agricultural users. Due to the statistical analysis of some epidemiologic studies the International Agency for Research on Cancer classified the broad-spectrum herbicide Glyphosate (GS) in 2015, as potentially carcinogenic to humans especially with respect to non-Hodgkin lymphoma (NHL). In this systematic review and re-analysis, the relationship between Glyphosate and NHL was re- investigated.

Methods: A systematic review and re-analysis of studies which investigated the relationship between GS and NHL was conducted. The method of the conditio sine qua non relationship, the method of the conditio per quam relationship, the method of the exclusion relationship and the mathematical formula of the causal relationship k were used to proof the hypothesis. Significance was indicated by a p-value of less than 0.05 . Results: The studies analyzed do not provide any direct and indirect evidence that NHL is caused GS.
\end{abstract}

Conclusion: In this re-analysis, no causal relationship was apparent between Glyphosate and NHL and its subtypes.

Keywords: Glyphosate, Non-Hodgkin lymphoma, no causal relationship

Article Info: $\quad$ Received 19 Dec 2019; $\quad$ Review Completed 04 Jan 2020; $\quad$ Accepted 14 Jan 2020; $\quad$ Available online 15 Feb 2020

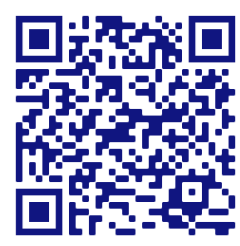

Cite this article as:

Barukčić I, Glyphosate and Non-Hodgkin lymphoma: No causal relationship, Journal of Drug Delivery and Therapeutics. 2020; 10(1-s):6-29 http://dx.doi.org/10.22270/jddt.v10i1-s.3856

*Address for Correspondence:

Ilija Barukčić, Horandstrasse, DE-26441 Jever, Germany

\section{INTRODUCTION}

Historically, Marcell Malpighi (1628-1694) described in 1666 as one of the first authors Hodgkin lymphoma (HL) in his publication: De viscerum structura exercitatio anatomica ${ }^{1}$. Centuries later, the English physician Thomas Hodgkin (17981866) of Guy's Hospital, London, published 1832 a remarkable paper entitled as "On some morbid cases of the absorbent glands and spleen" 2 and described a new disease, in medical literature known through the use of the term 'Hodgkin's disease' 3 . Lymphomas are traditionally divided into non-Hodgkin ISSN: 2250-1177 lymphoma and Hodgkin's lymphoma, which are responsible for about $10 \%$ of all lymphomas ${ }^{4}$ and known since centuries too. Independently of Hodgkin, the non-Hodgkin lymphoma i. e. leukaemia were described by Virchow ${ }^{5}$, Bennett ${ }^{6}$ and by Cohnheim ${ }^{7}$ too under the descriptive term 'pseudoleukaemia. Non-Hodgkin lymphoma (NHL) is a group of blood cancers with a wide range of histological appearances and clinical features at presentation which includes all different types of lymphoma but Hodgkin's lymphomas. The first systematic and widely accepted classification of lymphomas other than Hodgkin was proposed by 
Henry Rappaport in $1956^{8}$. Meanwhile, NHL is the leading hematological malignancy worldwide. Non-Hodgkin lymphoma (also known as non-Hodgkin's lymphoma, NHL, or sometimes just lymphoma) starts when white blood cells called (B- or T-) lymphocytes begin to grow out of control. NHL can start anywhere in the body but is usually found in lymph nodes or other lymph tissues (spleen, bone marrow, thymus, adenoids and tonsils, digestive tract). Several NHL risk factors like age, gender, family history, weakened immune system, radiation exposure, exposure to certain chemicals and drugs and Glyphosate too have been discussed in literature, but the cause or a cause of NHL has not been identified. Finally, in 2015, the International Agency for Research on Cancer ${ }^{9}$ Working Group published limited evidence of increased risk of non-Hodgkin lymphoma (NHL) in some epidemiologic studies. Glyphosate [N-(phosphonomethyl)glycine] itself, sold in the commercial as Roundup ${ }^{\circledR}$ (Monsanto Company, St. Louis, MO), was registered in the U.S. in 1974 and re-registrated 1993 by the US Environmental Protection Agency ${ }^{10}$. Since its introduction in the 1970s Glyphosate has been frequently ${ }^{11}$ used in forestry, in cropland and noncropland areas like gardens and lawns et cetera to control vegetation. Especially after genetically engineered Glyphosate-tolerant crops were introduced, the use of Glyphosate increased dramatically in the late-1990s and 2000s. Glyphosate inhibits the enzyme 5-enolpyruvylshikimate-3-phosphate synthase ${ }^{12}$, which is responsible via a mechanism specific to plants for the biosynthesis of aromatic amino acids like phenylalanine, tyrosine, and tryptophan. Questions regarding the safety of Glyphosate, its major breakdown product aminomethylphosphonic acid (AMPA) and the predominant surfactant polyethoxylated tallow amine (POEA) have been periodically raised ${ }^{13-21}$ raised. In the following, different studies have been conducted by several regulatory agencies and scientific institutions worldwide to re-evaluate the relationship between the use of Glyphosate or contact with Glyphosate and view other events. Glyphosate had no effects on fertility or reproductive parameters, there was no convincing evidence for direct DNA damage in vitro or in vivo, and neither AMPA nor Glyphosate bioaccumulates in any animal tissue ${ }^{11}$. Nevertheless, the question whether Glyphosate does pose a health risk to humans has not been finally answered. Thus far, considering use of Glyphosate in both the United States and the rest of the world, an ongoing risk assessment is necessary. Here we have re-investigated the relationship between GS and NHL by re-analyzing studies publicly available by new statistical methods.

\section{MATERIAL AND METHODS}

In one way or another, testing hypotheses and theories about the natural world is not completely free of errors. Still, when all goes well, a systematic observation and experimentation has the potential to assure that different scientists at different times and places independently of any ideology and individual motivation should be able to generate the same scientific knowledge.

\subsection{Definitions}

Definition 2.1.1. (The $2 \times 2$ Table)

A two by two table (also called a contingency table, a notion first used by Karl Pearson ${ }^{22}$ in 1904) is a useful tool for examining relationships between Bernoulli (i. e. Binomial) distributed random variables. Consider the case of a Bernoulli distributed random variable $A_{t}$ occurring/existing et cetera with the probability $p\left(A_{t}\right)$ at the Bernoulli trial (period of time) $t$. Furthermore, consider the case of another Bernoulli distributed random variable $B_{t}$ occurring/existing et cetera with the probability $\mathrm{p}\left(\mathrm{B}_{\mathrm{t}}\right)$ at the same Bernoulli trial (period of time) t. Furthermore, let $\mathrm{p}\left(\mathrm{a}_{\mathrm{t}}\right)=\mathrm{p}\left(\mathrm{A}_{\mathrm{t}} \cap \mathrm{B}_{\mathrm{t}}\right)$ denote the joint probability distribution of $A_{t}$ and $B_{t}$ at the same Bernoulli trial (period of time) t. The following table (Table 1) may show the relationships in more details.

Table 1 . The probabitlities of a contingency table

\begin{tabular}{|c|c|c|c|c|}
\hline \multirow{4}{*}{$\begin{array}{l}\text { Condition A } \\
\text { ("risk factor") }\end{array}$} & & \multicolumn{2}{|c|}{$\begin{array}{c}\text { Conditioned B } \\
\text { ("Outcome") }\end{array}$} & \multirow[b]{2}{*}{ Total } \\
\hline & & Yes $=+1$ & No $=+0$ & \\
\hline & Yes $=+1$ & $\mathrm{p}\left(\mathrm{a}_{\mathrm{t}}\right)$ & $\mathrm{p}\left(\mathrm{b}_{\mathrm{t}}\right)$ & $p\left(A_{t}\right)$ \\
\hline & $\mathrm{No}=+0$ & $\mathrm{p}\left(\mathrm{c}_{\mathrm{t}}\right)$ & $\mathrm{p}\left(\mathrm{d}_{\mathrm{t}}\right)$ & $\mathrm{p}\left(\underline{\mathrm{A}}_{t}\right)$ \\
\hline & Total & $\mathrm{p}\left(\mathrm{B}_{\mathrm{t}}\right)$ & $\mathrm{p}\left(\underline{\mathrm{B}}_{\mathrm{t}}\right)$ & 1 \\
\hline
\end{tabular}


In this context, it is per definitionem

\begin{tabular}{|c|c|c|c|c|}
\hline$p\left(A_{t}\right)$ & $\equiv$ & $p\left(a_{t}\right)+p\left(b_{t}\right)$ & $=$ & $1-p\left(\underline{A}_{t}\right)$ \\
\hline$p\left(B_{t}\right)$ & $\equiv$ & $p\left(a_{t}\right)+p\left(c_{t}\right)$ & $=$ & $1-p\left(\underline{B}_{t}\right)$ \\
\hline$p\left(a_{t}\right)$ & $\equiv$ & $p\left(A_{t} \cap B_{t}\right)$ & $=$ & $1-p\left(b_{t}\right)-p\left(c_{t}\right)-p\left(d_{t}\right)$ \\
\hline+1 & $\equiv$ & $p\left(a_{t}\right)+p\left(b_{t}\right)$ & + & $p\left(c_{t}\right)+p\left(d_{t}\right)$ \\
\hline+1 & $\equiv$ & $p\left(A_{t}\right)+p\left(\underline{A}_{t}\right)$ & $=$ & $p\left(B_{t}\right)+p\left(\underline{B}_{t}\right)$ \\
\hline$p\left(B_{t}\right)+p\left(\Lambda_{t}\right)$ & $\equiv$ & $p\left(A_{t}\right)$ & $=$ & $1-p\left(\underline{B}_{t}\right)+p\left(\Lambda_{t}\right)$ \\
\hline$p\left(\underline{A}_{t}\right)$ & $=$ & $1-\left(1-p\left(\underline{B}_{t}\right)+p\left(\Lambda_{t}\right)\right)$ & $=$ & $p\left(\underline{B}_{t}\right)-p\left(\Lambda_{t}\right)$ \\
\hline$p\left(\Lambda_{t}\right)$ & $=$ & $p\left(A_{t}\right)-p\left(B_{t}\right)$ & $=$ & $p\left(b_{t}\right)-p\left(c_{t}\right)$ \\
\hline$p\left(b_{t}\right)+p\left(c_{t}\right)$ & $=$ & $\left(2 \times p\left(c_{t}\right)\right)+p\left(\Lambda_{t}\right)$ & $=$ & $1-p\left(a_{t}\right)-p\left(d_{t}\right)$ \\
\hline
\end{tabular}

while +1 denotes the normalized sample space of $\mathrm{A}_{t}$ and $\mathrm{B}_{\mathrm{t}}$. We obtain some of the relationships per definitionem

$$
\begin{array}{rlccc}
A & \equiv & n \times p\left(a_{t}\right)+n \times p\left(b_{t}\right) & = & n \times p\left(A_{t}\right) \\
B & \equiv & n \times p\left(a_{t}\right)+n \times p\left(c_{t}\right) & = & n \times p\left(B_{t}\right) \\
a & \equiv & n \times p\left(a_{t}\right) & = & n \times p\left(A_{t} \cap B_{t}\right) \\
b & \equiv & n \times p\left(b_{t}\right) & & \\
c & \equiv & n \times p\left(c_{t}\right) & & \\
d & \equiv & n \times p\left(d_{t}\right) & & \\
n & \equiv & n \times p\left(a_{t}\right)+n \times p\left(b_{t}\right) & + & n \times p\left(c_{t}\right)+n \times p\left(d_{t}\right) \\
n & \equiv & n \times p\left(A_{t}\right)+n \times p\left(\underline{A}_{t}\right)= & n \times p\left(B_{t}\right)+n \times p\left(\underline{B}_{t}\right)
\end{array}
$$

\begin{tabular}{|c|c|c|c|c|}
\hline & & \multicolumn{2}{|c|}{$\begin{array}{l}\text { Conditioned B } \\
\text { ("Outcome") }\end{array}$} & \multirow[b]{2}{*}{ Total } \\
\hline & & Yes $=+1$ & No $=+0$ & \\
\hline \multirow{3}{*}{$\begin{array}{l}\text { Condition A } \\
\text { ("risk factor") }\end{array}$} & Yes $=+1$ & $\mathrm{a}$ & $\mathrm{b}$ & A \\
\hline & $\mathrm{No}=+0$ & $\mathrm{c}$ & $\mathrm{d}$ & $\underline{\mathrm{A}}$ \\
\hline & Total & B & $\underline{B}$ & $n$ \\
\hline
\end{tabular}

The meaning of the abbreviations a, b, c, d, n et cetera are explained by following 2 by 2 -table (Table 2).

Table 2. The sample space of a contingency table

\section{Definition 2.1.2. (Fisher's exact test)}

Many times, the sampling distribution of a test statistic calculated is only approximately equal to the theoretical chi-squared distribution. Under these circumstances, a chi-squared test provides approximative significance values. The approximation by a chi-squared distribution is inadequate when the data are very unequally distributed or sample sizes are small. Fisher 23 developed an exact statistical significance test for the analysis of contingency tables valid for all sample sizes. The one sided right tailed $\mathrm{P}$ Value given by the hypergeometric distribution can be calculated ${ }^{24}$ as

$$
p_{\text {Fisher }}(X \geq a)=\frac{(A !) \times(\underline{A} !) \times(B !) \times(\underline{B} !)}{(a !) \times(b !) \times(d !) \times(d !) \times(n !)}
$$


In short, Fisher's exact one sided right tailed test computes the $\mathrm{P}$

Value according to the hypergeometric distribution ${ }^{25(\mathrm{p} 121)}$ using

$$
P \text { Value one sided right tailed }(X \geq a)=1-\sum_{t=0}^{a-1} \frac{\left(\left(\begin{array}{c}
A \\
t
\end{array}\right) \times\left(\begin{array}{l}
n-A \\
B-t
\end{array}\right)\right)}{\left(\begin{array}{l}
n \\
B
\end{array}\right)}
$$

The deviation from a null hypothesis (e.g., P-value) is calculated exactly, rather than relying on an approximation. To put it another way, the null hypothesis of Fisher's exact non parametric test is that the relative proportion $\mathrm{A}$ is independent of the relative proportion $\mathrm{B}$. As soon as the resulting $\mathrm{P}$ Value is smaller than a significance level Alpha, the null hypothesis that A and B are independent can be rejected.

\subsection{Material}

2.2.1 Search Strategy
To answer the questions addressed in this paper, the electronic database PubMed was searched for appropriate studies conducted in any country which investigated the relationship between Glyphosate and NHL. The search in PubMed was performed while using some medical key words. Those articles were considered for a re-view which provided access to data without any data access barrier. Additionally, the reference list of identified articles was used as a potential source of articles appropriate for this study. The screening process and results are shown in Table 3 while following the Preferred Reporting Items for Systematic Reviews and Meta - analysis (PRISMA) ${ }^{26,27}$.

Table 3 .

\begin{tabular}{|c|c|c|}
\hline 1. Identification of records & Size & Total \\
\hline \multicolumn{3}{|l|}{ Records identified by searching in the databases } \\
\hline PubMed & 9 & \\
\hline Google Scholar & 0 & \\
\hline \multicolumn{3}{|l|}{ Web of Science } \\
\hline Additional records identified from other sources & 2 & 11 \\
\hline \multicolumn{3}{|l|}{ 2. Clean-up of search (Screening) } \\
\hline Records removed after verifying duplication & 0 & \\
\hline Records excluded by title & 2 & \\
\hline Records excluded due to other reasons & 2 & \\
\hline \multicolumn{3}{|l|}{ (Articles outside the inclusion criteria) } \\
\hline \multicolumn{3}{|l|}{ 3. Eligibility } \\
\hline \multicolumn{3}{|l|}{ Articles evaluated for eligibility } \\
\hline \multicolumn{3}{|l|}{ Articles excluded for various reasons } \\
\hline Language & 0 & \\
\hline Data access barriers & 0 & \\
\hline
\end{tabular}

\section{Included}

Articles included in the meta-analysis 7

Flow Diagram of the article selection process. Adopted from PRISMA $2009^{26,27}$. 


\section{Ilija Barukčić}

The study of Hardell and Eriksson ${ }^{28}$ published (4/404) positive cases and (3/741) positive controls but was not considered for a re-analyses. The data of this study are extremely self-contradictory. The index of unfairness is IOU $=-0.64$ and highly unfair. At the same time, the exclusion relationship between GS and NHL is positive ( $\mathrm{p}(\mathrm{EXCL})=0,99650655, \mathrm{X}^{2}$ $(\mathrm{EXCL})=0,04$ and $\left.\mathrm{X}^{2}(\mathrm{EXCL})=2,29\right)$ while equally the conditio per quam relationship is significant too ( $p$ (IMP) $=0,997379913 . X^{2}\left(\right.$ IMP) $=0,01 \cdot X^{2}($ IMP) $=1,29)$. This is a contradiction. Mathematically, it is not possible GS excludes NHL and at the same time that if GS then NHL. Leon et al. ${ }^{29}$ investigated the relationship of ever use of Glyphosate and non-Hodgkin lymphoid malignancies (NHL) in a pooled analysis of three large agricultural worker cohorts of 316270 farmers. A control group has not been provided. During follow-up, 2430 NHL cases were diagnosed while 1131 of these cases ever used Glyphosate. Besides of a missing control group, a fair study design assumed, it is possible to calculate the significance of a conditio sine qua non relationship between GS and NHL as $\mathrm{X}^{2}(\mathrm{SINE})=((2430-1131) *(2430-1131)) / 2430=694,41$, a highly significant result. In other words, the study of Leon et al. has provided striking evidence that GS is not a necessary condition of NHL. In other words, it is possible to suffer from NHL without GS. According to Leon et al. ${ }^{29}$ the Null-hypothesis: without GS no NHL must be rejected. The consequence is, that the use of GS must imply that people will suffer from NHL, which is not the case either.

\subsubsection{Statistical Analysis}

The causal relationship $\mathrm{k}^{30-39}$ is defined at every single event $32,35-37,40,41$, at every single Bernoulli trial ${ }^{42(\mathrm{p} 45)} t$ and was used to proof the data for a causal relationship while the significance was tested by the hypergeometric distribution (HGD) and sometimes by the chi-square distribution ${ }^{43}$ too. The conditio sine qua non 30,31,34-37,37,40,44 relationship (SINE) was used to proof the hypothesis, without ${ }^{45}$ GS no NHL. The conditio per quam ${ }^{30,31,34}$ $37,37,40,44$ relationship (IMP) was used to proof the hypothesis, if ${ }^{45}$ GS then NHL. The necessary and sufficient condition ${ }^{30,31,34-}$ $37,37,40,44$ relationship (SINE) can be used to proof the hypothesis, (without GS no NHL) and (if GS then NHL). The exclusion 30,31,34-37,37,40,44 relationship (EXCL) was used to proof the hypothesis, GS excludes NHL. The index of unfairness ${ }^{46}$ and the index of independence ${ }^{47}$ were used to check the data available for publication bias. All statistical analyses were performed with
Journal of Drug Delivery \& Therapeutics. 2020; 10(1-s):6-29

Microsoft $₫$ Excel $₫$ for Mac $₫$ version 16.2 (181208) software ( ( 2018, Microsoft GmbH, Munich, Germany). The level of significance was set to 0.05 .

\section{RESULTS}

Theorem 3.1. (Glyphosate is neither a cause nor the cause of Non-Hodgkin Lymphoma.)

McDuffie et al. ${ }^{48}$ conducted a Canadian multicenter population-based incident, case $(\mathrm{n}=517)$-control $(\mathrm{n}=1506)$ study to investigate the putative associations of specific pesticides with non-Hodgkin's Lymphoma.

\section{Claim.}

\section{Null Hypothesis:}

Glyphosate is neither the cause nor a cause of Non-Hodgkin Lymphoma. In other words, $\mathrm{k}=0$.

\section{Alternative Hypothesis:}

Glyphosate is either the cause or a cause of Non-Hodgkin Lymphoma. In other words, $\mathrm{k}>0$.

\section{Proof.}

McDuffie et al. investigated the relationship between exposure to Glyphosate of humans with respect to the development of Non-Hodgkin Lymphoma. The data as obtained by McDuffie et al. ${ }^{48}$ are view by table 4 . The index of independence of the study of McDuffie et al. is $\mathrm{p}(\mathrm{IOI})=0,165$ and implies that the data of the study of McDuffie et al. can be considered for the re-analysis of causal relationship and for the re-analysis of the exclusion relationship. The index of unfairness of this study is $\mathrm{p}(\mathrm{IOU})=$ 0,653 and indicates potentially biased data. Altogether, the data as published by the study of McDuffie et al. are more or less not absolutely biased. The relative frequency of the conditio sine qua non relationship (SINE) between GS and NHL is $\mathrm{p}$ (SINE) $=0,770$. Thus far, the approximate $\mathrm{P}$ Value ${ }^{49}$ can be calculated as $\mathrm{P}$ Value $(\mathrm{SINE})=0,206$. The significance of these data tested by the Chi-square goodness of fit test (sample size $n=2023$ ) yields the following results, while the $\mathrm{X}^{2}$ critical (degrees of freedom = 1, Alpha 0,05$)$ is $\mathrm{X}^{2}$ (critical) $=3,84145882$. Firstly. The data demand that the calculated $\mathrm{X}^{2}\left(\operatorname{SINE} \mid \mathrm{B}_{\mathrm{t}}\right)$ is $\mathrm{X}^{2}\left(\mathrm{SINE} \mid \mathrm{B}_{\mathrm{t}}\right)=$ $(((466) *(466) / 517)+0=420,031$. Secondly. The same data demand that the calculated $X^{2}\left(\operatorname{SINE} \mid \underline{A}_{t}\right)$ is $X^{2}\left(\operatorname{SINE} \mid \underline{A}_{t}\right)=(((466$

)$\left.\left.^{*}(466)\right) / 1839\right)+0=118,084$. The data of the study of McDuffie et al. do not support the hypothesis that GS is a 


\section{Ilija Barukčić}

necessary condition of NHL. In other words, the hypothesis: without GS no NHL cannot be accepted. Furthermore, mathematically a positive causal relationship, even if not significant, does not contradict formally the hypothesis of a conditio sine qua non relationship. According to the data of the study of McDuffie et al. it is possible to suffer from NHL without having any contact with GS. The relative frequency of the
Journal of Drug Delivery \& Therapeutics. 2020; 10(1-s):6-29 conditio per quam relationship (IMP) between GS and NHL is $\mathrm{p}(\mathrm{IMP})=0,934$. The approximate $\mathrm{P}$ Value ${ }^{49}$ can be calculated as $\mathrm{P}$ Value $(\mathrm{IMP})=0,064$. The significance of these data tested by the Chi-square goodness of fit test (sample size $n=2023$ ) yields the following results, while the $\mathrm{X}^{2}$ critical (degrees of freedom $=$ 1, Alpha 0,05$)$ is $\mathrm{X}^{2}$ (critical) $=3,84145882$.

Table 4

The study of McDuffie et al., 2001.

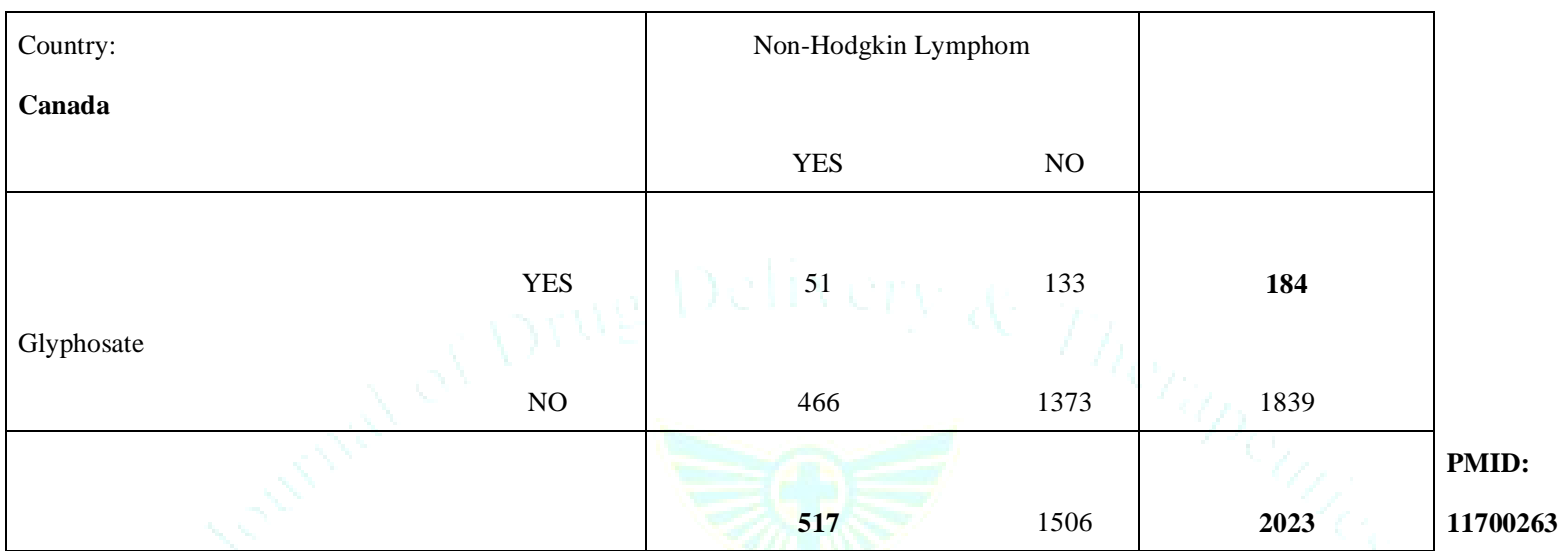

\begin{tabular}{|c|c|c|c|c|c|}
\hline Causal relationship $k=$ & 0,016 & $95 \% \mathrm{CI}(\mathrm{k}):$ & $-0,034$ & to & 0,065 \\
\hline$P$ value $(k \mid$ HGD $)=$ & 0,26647 & Chi Sq. $(k)=$ & 0,497 & & \\
\hline $\mathbf{p}(\mathrm{IOI})=$ & 0,165 & $\mathbf{p}(\mathbf{I O U})=$ & 0,653 & $p(I O U)+p(I O I)=$ & $\mathbf{0 , 8 1 8}$ \\
\hline$p($ SINE $)=$ & $\mathbf{0 , 7 7 0}$ & $\mathrm{X}^{2}(\mathrm{SINE} \mid \mathrm{Bt})=$ & 420,031 & $\mathrm{X}^{2}(\mathrm{SINE} \mid \underline{\mathbf{A}} \mathrm{t})=$ & 118,084 \\
\hline P likely $($ SINE) $=$ & 0,794 & $\mathrm{P}$ Value (SINE) $=$ & 0,206 & & \\
\hline $\mathbf{p}(\mathbf{I M P})=$ & 0,934 & $\left.\mathbf{X}^{2}(\mathbf{I M P} \mid \mathbf{A t})\right)=$ & 96,136 & $\mathbf{X}^{2}(\mathbf{I M P} \mid \underline{B} t)=$ & 11,746 \\
\hline P likely $($ IMP) $=$ & 0,936 & $\mathrm{P}$ Value $(\mathrm{IMP})=$ & 0,064 & & \\
\hline $\mathrm{p}(\mathrm{SINE} \wedge$ IMP $)=$ & 0,704 & $\mathrm{X}^{2}\left(\mathrm{SINE}^{\wedge} \mathrm{IMP} \mid \mathrm{At}\right)=$ & 431,777 & $\mathrm{X}^{2}\left(\mathrm{SINE}^{\wedge} \mathrm{IMP} \mid \mathrm{Bt}\right)=$ & 431,777 \\
\hline $\mathrm{p}$ likely $\left(\mathrm{SINE}^{\wedge} \mathrm{IMP}\right)=$ & 0,744 & $\mathrm{p}$ Value $\left(\mathrm{SINE}^{\wedge} \mathrm{IMP}\right)=$ & 0,256 & & \\
\hline p $($ EXCL $)=$ & 0,975 & $\mathbf{X}^{2}(\mathbf{E X C L} \mid \mathbf{A t})=$ & 14,136 & $X^{2}(\operatorname{EXCL} \mid B t)=$ & 5,031 \\
\hline$P($ Likely EXCL $)=$ & 0,975 & $P$ Value $(E X C L)=$ & 0,025 & & \\
\hline Odds ratio $(\mathrm{OR})=$ & 1,130 & $95 \%$ CI (OR) : & 0,805 & to & 1,587 \\
\hline
\end{tabular}

Firstly. The data demand that the calculated $\mathrm{X}^{2}\left(\mathrm{IMP} \mid \mathrm{A}_{\mathrm{t}}\right)$ is $\mathrm{X}^{2}\left(\operatorname{IMP} \mid \mathrm{A}_{\mathrm{t}}\right)=\left(\left((133)^{*}(133)\right) / 184\right)+0=96,136$. Secondly. The same data demand that the calculated $\mathrm{X}^{2}\left(\mathrm{IMP} \mid\right.$ Not $\left.B_{t}\right)$ is $\mathrm{X}^{2}\left(\mathrm{IMP} \mid \operatorname{Not} \mathrm{B}_{\mathrm{t}}\right)=(((133) *(133)) / 1506)+0=11,746$. The data of the study of McDuffie et al. do not support the hypothesis that GS is a sufficient condition of NHL. Furthermore, mathematically a positive causal relationship, even if not significant, does not contradict the hypothesis of a conditio per quam relationship. Based on the data of the study of McDuffie et al. it is necessary to conclude the following: People who have contact with GS will not suffer from NHL due to Glyphosate. Contrary to expectation, the use of GS or a contact with GS can have 


\section{Ilija Barukčić}

protective effects against NHL. In this case we expect a significant negative causal relationship $\mathrm{k}$ and a significant exclusion relationship. The relative frequency of the exclusion relationship (EXCL) between GS and NHL is $\mathrm{p}(\mathrm{EXCL})=0,975$. The approximate $\mathrm{P}$ Value can be calculated as $\mathrm{P}$ Value $(\mathrm{EXCL})=$ 0,025 and is significant. In other words, GS excludes NHL and protects against NHL. The index of independence of the study of McDuffie et al. is $\mathrm{p}(\mathrm{IOI})=0,165$ with the consequence that the data can be used for these purposes. However, the significance of these data tested by the Chi-square goodness of fit test (sample size $n=2023$ ) yields the following results while the $X^{2}$ critical $($ degrees of freedom $=1$, Alpha 0,05$)$ is $\mathrm{X}^{2}($ critical $)=$ 3,84145882. Firstly. The data demand that the calculated $\mathrm{X}^{2}(\mathrm{EXCL} \mid \mathrm{At})$ is $\mathrm{X}^{2}(\mathrm{EXCL} \mid \mathrm{At})=(((51) *(51)) / 184)+0=14,136$. Secondly. The same data demand that the calculated $\mathrm{X}^{2}(\mathrm{EXCL} \mid \mathrm{Bt})$ is $\mathrm{X}^{2}(\mathrm{EXCL} \mid \mathrm{Bt})=\left(\left((51)^{*}(51)\right) / 517\right)+0=5,031$. Based on the Chi square distribution, the data of the study of McDuffie et al. do not support the hypothesis that GS excludes NHL. Furthermore, the causal relationship is positive. However, mathematically it is not possible to obtain a positive causal relationship and at the same time a significant exclusion relationship. Therefore, the conclusion is not justified that the study of McDuffie et al. supports the hypothesis that GS excludes NHL. The causal relationship $\mathrm{k}$ is $\mathrm{k}=0,016$ and positive while the approximate $95 \%$ confidence interval of the causal relationship $\mathrm{k}$ is between $-0,034$ and 0,065 . The right tailed $\mathrm{P}$ Value of the causal relationship $\mathrm{k}$ calculated according to the hypergeometric distribution is $\mathrm{P}$ Value $(\mathrm{k} \mid \mathrm{HGD})=0,26647$ and not significant. Conclusion. There is no positive cause-effect relationship between GS and NHL. Thus far, according to the data of McDuffie et al., Glyphosate is neither a cause nor the cause of Non-Hodgkin Lymphoma.

\section{Quod erat demonstrandum.}

Theorem 3.2. (Glyphosate is neither a cause nor the cause of Non-Hodgkin Lymphoma.)

Hardell, Eriksson, \& Nordstrom ${ }^{50}$ investigated the importance of Glyphosate and other factors in the etiology of NHL by a pooled analysis performed on two case-control studies. Hardell, Eriksson, \& Nordstrom reported that they were not able to find an association between Glyphosate and non-Hodgkin lymphoma.
Journal of Drug Delivery \& Therapeutics. 2020; 10(1-s):6-29

Claim.

\section{Null Hypothesis:}

Glyphosate is not a cause of Non-Hodgkin Lymphoma. In other words, $\mathrm{k}=0$.

\section{Alternative Hypothesis:}

Glyphosate is a cause of Non-Hodgkin Lymphoma. In other words, $\mathrm{k}>0$.

\section{Proof.}

The data as obtained by Hardell, Eriksson, \& Nordstrom (Hardell, Eriksson, \& Nordstrom, 2002) are viewed by table 5. The index of independence of the study of Hardell, Eriksson, \& Nordstrom et al. is $p(I O I)=0,301$ and implies that the data of the study of Hardell, Eriksson, \& Nordstrom et al. are of some but very restricted value to be considered for the re-analysis of causal relationship or for the re-analysis of the exclusion relationship. In contrast to IOI, the index of unfairness ${ }^{46}$ of this study is $\mathrm{p}(\mathrm{IOU})=$ 0,679 and indicates potentially biased data. Altogether, the data as published by the study of Hardell, Eriksson, \& Nordstrom et al. can be used only with very great care for a re-analysis. The relative frequency of the conditio sine qua non relationship between GS and NHL is $\mathrm{p}(\mathrm{SINE})=0,694$. The approximate $\mathrm{P}$ Value can be calculated as $\mathrm{P}$ Value $(\mathrm{SINE})=0,264$, the relationship is not significant. The significance of these data tested by the Chi-square goodness of fit test (sample size $n=$ 1656) yields the following results while the $X^{2}$ critical (degrees of freedom $=1$, Alpha 0,05) is $\mathrm{X}^{2}($ critical $)=3,84145882$. Firstly. The data of the study of Hardell, Eriksson, \& Nordstrom et al. demand that the calculated $\mathrm{X}^{2}(\mathrm{SINE} \mid \mathrm{Bt})$ is $\mathrm{X}^{2}(\mathrm{SINE} \mid \mathrm{Bt})=$ $(((507) *(507)) / 515)+0=499,124$. Secondly. The same data demand that the calculated $\mathrm{X}^{2}$ (SINE|Not At) is $\mathrm{X}^{2}$ (SINE|Not At) $=(((507) *(507)) / 1640)+0=156,737$ while the cause effect relationship is positive! The data of the study of Hardell, Eriksson, \& Nordstrom et al. do not support the hypothesis that GS is a necessary condition of NHL. According to the data of the study of Hardell, Eriksson, \& Nordstrom et al. it is possible to suffer from NHL without any contact to GS. 
Table 5

The study of Hardell, Eriksson, \& Nordstrom et al., 2002.

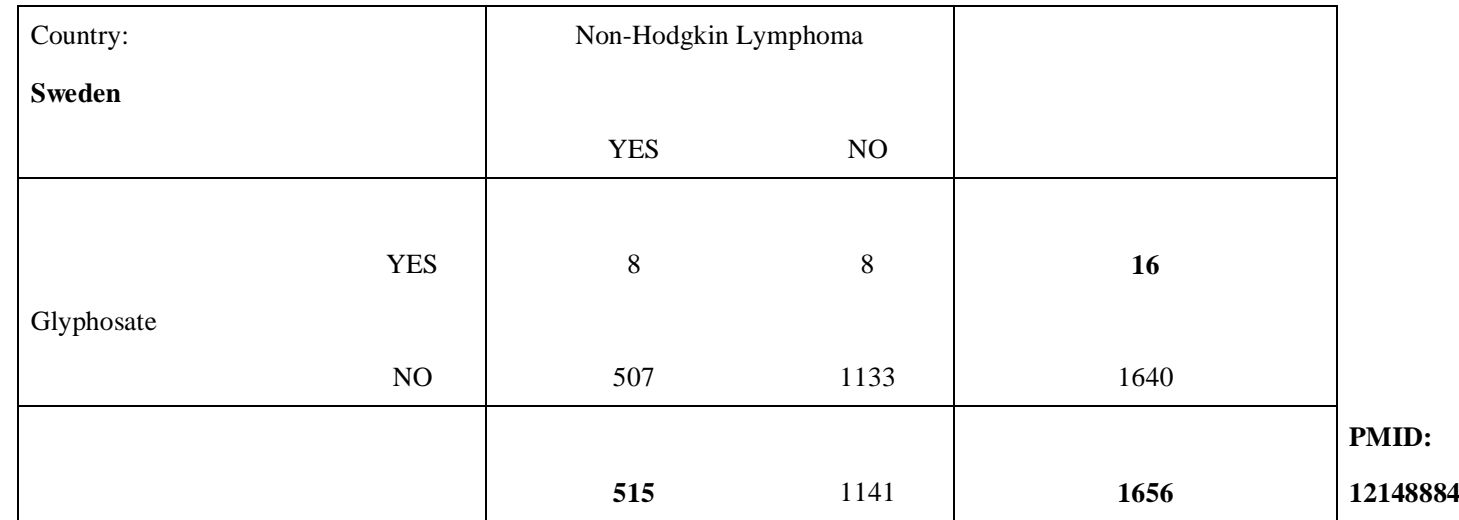

\begin{tabular}{|c|c|c|c|c|c|}
\hline \multicolumn{6}{|l|}{ Statistical analysis } \\
\hline Causal relationship $\mathrm{k}=$ & $+0,040$ & $95 \% \mathrm{CI}(\mathrm{k}):$ & $-0,015$ & to & 0,095 \\
\hline$P$ value $(k \mid$ HGD $)=$ & 0,08852 & Chi Sq. $(k)=$ & 2,694 & & \\
\hline $\mathbf{p}(\mathbf{I O I})=$ & $\mathbf{0 , 3 0 1}$ & $\mathbf{p}(\mathbf{I O U})=$ & 0,679 & $\mathbf{p}($ IOU $)+\mathbf{p}($ IOI $)=$ & 0,981 \\
\hline p $($ SINE $)=$ & 0,694 & $\mathrm{X}^{2}(\mathrm{SINE} \mid \mathrm{Bt})=$ & 499,124 & $\mathrm{X}^{2}(\mathrm{SINE} \mid \underline{\mathrm{At}} \mathrm{t})=$ & 156,737 \\
\hline $\mathrm{P}$ likely $(\mathrm{SINE})=$ & 0,736 & $\mathrm{P}$ Value $(\mathrm{SINE})=$ & 0,264 & & \\
\hline $\mathbf{p}(\mathbf{I M P})=$ & 0,995 & $\left.\mathrm{X}^{2}(\mathrm{IMP} \mid \mathrm{At})\right)=$ & 4,000 & $\mathbf{X}^{2}(\mathrm{IMP} \mid \underline{B} \mathrm{t})=$ & 0,056 \\
\hline $\mathrm{P}$ likely $(\mathrm{IMP})=$ & 0,995 & $\mathrm{P}$ Value $(\mathrm{IMP})=$ & 0,005 & & \\
\hline $\mathrm{p}\left(\mathrm{SINE}^{\wedge} \mathrm{IMP}\right)=$ & 0,689 & $\mathrm{X}^{2}\left(\mathrm{SINE}^{\wedge} \mathrm{IMP} \mid \mathrm{At}\right)=$ & 499,180 & $\mathrm{X}^{2}\left(\mathrm{SINE}^{\wedge} \mathrm{IMP} \mid \mathrm{Bt}\right)=$ & 499,180 \\
\hline p likely $\left(\mathrm{SINE}^{\wedge} \mathrm{IMP}\right)=$ & 0,733 & $\mathrm{p}$ Value $\left(\mathrm{SINE}^{\wedge} \mathrm{IMP}\right)=$ & 0,267 & & \\
\hline $\mathbf{p}(\mathbf{E X C L})=$ & 0,995 & $\mathrm{X}^{2}(\mathrm{EXCL} \mid \mathrm{At})=$ & 4,000 & $\mathrm{X}^{2}(\mathrm{EXCL} \mid \mathrm{Bt})=$ & 0,124 \\
\hline$P($ Likely EXCL $)=$ & 0,995 & $P$ Value $(E X C L)=$ & 0,005 & & \\
\hline Odds $\operatorname{ratio}(\mathrm{OR})=$ & 2,235 & $95 \%$ CI (OR) : & 0,834 & to & 5,988 \\
\hline
\end{tabular}

The relative frequency of the conditio per quam relationship between GS and NHL is $\mathrm{p}(\mathrm{IMP})=0,995$. The approximate $\mathrm{P}$ Value can be calculated as $\mathrm{P}$ Value $(\mathrm{IMP})=0,005$. The significance of these data tested by the Chi-square goodness of fit test (sample size $\mathrm{n}=1656$ ) yields the following results while the $\mathrm{X}^{2}$ critical (degrees of freedom $=1$, Alpha 0,05$)$ is $\mathrm{X}^{2}($ critical $)=$ 3,84145882. Firstly. The data demand that the calculated $\mathrm{X}^{2}(\mathrm{IMP} \mid \mathrm{At})$ is $\mathrm{X}^{2}(\mathrm{IMP} \mid \mathrm{At})=\left(\left((8)^{*}(8)\right) / 16\right)+0=4,000$ which is not significant. Secondly. The same data demand that the calculated $\mathrm{X}^{2}(\mathrm{IMP} \mid \mathrm{Not} \mathrm{Bt})$ is $\mathrm{X}^{2}(\mathrm{IMP} \mid \mathrm{Not} \mathrm{Bt})=\left(\left((8)^{*}(8)\right) / 1141\right)$ $+0=0,056$, which is a significant result while the cause effect relationship is positive, but not significant. The data of the study of Hardell, Eriksson, \& Nordstrom et al. do support both: GS is a sufficient condition of NHL and the same data demand too that GS is not a sufficient condition of NHL which is a contradiction! The data of the study of Hardell, Eriksson, \& Nordstrom et al. are more or less biased as indicated by an $p(I O I)=0,301$ and cannot be used for these purposes. In point of fact, can the use of GS have any protective effects against NHL? In this case we expect a significant negative causal relationship $\mathrm{k}$ and a significant exclusion relationship. The relative frequency of the exclusion relationship between GS and NHL is p (EXCL) $=0,995$. The approximate $\mathrm{P}$ Value can be calculated as $\mathrm{P}$ Value $(\mathrm{EXCL})=0,005$. The significance of these data tested by the Chi-square goodness of fit test (sample size $n=1656$ ) yields the following results, while the $\mathrm{X}^{2}$ critical (degrees of freedom $=1$, Alpha 0,05) is $\mathrm{X}^{2}$ (critical) $=3,84145882$. Firstly. The data demand that the calculated $\mathrm{X}^{2}(\mathrm{EXCL} \mid \mathrm{At})$ is $\mathrm{X}^{2}(\mathrm{EXCL} \mid \mathrm{At})=$ $\left(\left((8)^{*}(8)\right) / 16\right)+0=4,000$, a non-significant result. Secondly. The same data demand too that the calculated $\mathrm{X}^{2}(\mathrm{EXCL} \mid \mathrm{Bt})$ is $\mathrm{X}^{2}(\mathrm{EXCL} \mid \mathrm{Bt})=(((8) *(8)) / 515)+0=0,124$, a significant result. The data of the study of Hardell, Eriksson, \& Nordstrom et al. support both: GS excludes NHL and the same data demand too that GS does not exclude NHL which is a contradiction! Furthermore, the causal relationship k is not negative. In toto, the data of the study of Hardell, Eriksson, \& Nordstrom et al. are 


\section{Ilija Barukčić}

self-contradictory, biased and cannot be used for our purposes. The causal relationship $\mathrm{k}$ is $\mathrm{k}=0,040$ and positive while the approximate $95 \%$ coincidence interval of the causal relationship $\mathrm{k}$ is between $-0,015$ and 0,095 . The one-sided right tailed $P$ Value of the causal relationship $\mathrm{k}$ calculated according to the hypergeometric distribution is P Value $(\mathrm{k} \mid \mathrm{HGD})=0,08852$ and not significant. Conclusion. There is no significant positive cause-effect relationship between GS and NHL. Thus far, if the data of the study of Hardell, Eriksson, \& Nordstrom et al. can provide anything valuable to the relationship between GS and NHL then only the fact that Glyphosate is neither a cause nor the cause of Non-Hodgkin Lymphoma.

\section{Quod erat demonstrandum.}

\section{Theorem 3.3. (Glyphosate is not a cause of Non-Hodgkin} Lymphoma.)

De Roos et al. ${ }^{51}$ examined whether an increased rate of non-Hodgkin's lymphoma (NHL) observed among farmers ${ }^{52}$ is due to pesticide exposures in farming. The term pesticide denotes a wide variety of chemicals used to destroy weeds (herbicides), insects (insecticides), and mold (fungicides).

\section{Claim.}

\section{Null Hypothesis:}

Glyphosate is not a cause of Non-Hodgkin Lymphoma. In other words, $\mathrm{k}=0$.
Journal of Drug Delivery \& Therapeutics. 2020; 10(1-s):6-29

\section{Alternative Hypothesis:}

Glyphosate is a cause of Non-Hodgkin Lymphoma. In other words, $\mathrm{k}>0$.

\section{Proof.}

De Roos et al. investigated the potential health effects of Glyphosate in humans with respect of the development of Non-Hodgkin Lymphoma. The data as obtained by De Roos et al. (De Roos et al., 2003) are view by table 6. The index of independence of the study of De Roos et al. ${ }^{51}$ is $\mathrm{p}(\mathrm{IOI})=0,209$. Thus far, the data of the study of De Roos et al. are of some even if restricted value to be considered for the re-analysis of the causal relationship and of the exclusion relationship. The index of unfairness of this study is $\mathrm{p}(\mathrm{IOU})=0,717$ and indicates extremely biased data. Altogether, the data as published by the study of De Roos et al. are more or less biased. The relative frequency of the conditio sine qua non relationship between GS and NHL is $p$ $(\mathrm{SINE})=0,768$. The approximate $\mathrm{P}$ Value can be calculated as $\mathrm{P}$ Value $(\mathrm{SINE})=0,207$. The significance of these data tested by the Chi-square goodness of fit test (sample size $n=2643$ ) yields the following result while the $\mathrm{X}^{2}$ critical (degrees of freedom $=1$, Alpha 0,05) is $\mathrm{X}^{2}$ (critical) $=3,84145882$. Firstly. Theses data demand that the calculated $\mathrm{X}^{2}(\mathrm{SINE} \mid \mathrm{Bt})$ is $\mathrm{X}^{2}(\mathrm{SINE} \mid \mathrm{Bt})=((($ $614) *(614)) / 650)+0=579,994$. Secondly. The same data demand that the calculated $\mathrm{X}^{2}(\mathrm{SINE} \mid \mathrm{Not} \mathrm{At})$ is $\mathrm{X}^{2}(\mathrm{SINE} \mid \mathrm{Not} \mathrm{At})$ $=(((614) *(614)) / 2546)+0=148,074$. The data of the study of De Roos et al. do not support the hypothesis that GS is a necessary condition of NHL! 
Table 6

The study of De Roos et al., 2003.

\begin{tabular}{|c|c|c|c|c|}
\hline $\begin{array}{l}\text { Country: } \\
\text { USA }\end{array}$ & & $\begin{array}{c}\text { Non-H } \\
\text { YES }\end{array}$ & $\mathrm{NO}$ & \\
\hline & YES & 36 & 61 & 97 \\
\hline & $\mathrm{NO}$ & 614 & 1932 & 2546 \\
\hline & & 650 & 1993 & 2643 \\
\hline
\end{tabular}

\begin{tabular}{|c|c|c|c|c|c|}
\hline \multicolumn{6}{|l|}{ Statistical analysis } \\
\hline Causal relationship $\mathrm{k}=$ & $+0,057$ & $95 \% \mathrm{CI}(\mathrm{k}):$ & 0,013 & to & 0,100 \\
\hline$P$ value $(k \mid H G D)=$ & 0,00351 & Chi Sq. $(\mathrm{k})=$ & 8,511 & & \\
\hline$p(I O I)=$ & 0,209 & $\mathbf{p}(\mathbf{I O U})=$ & $\mathbf{0 , 7 1 7}$ & $\mathbf{p}(\mathrm{IOU})+\mathbf{p}(\mathrm{IOI})=$ & 0,927 \\
\hline$p($ SINE $)=$ & 0,768 & $\mathbf{X}^{2}(\mathrm{SINE} \mid \mathrm{Bt})=$ & 579,994 & $\mathrm{X}^{2}(\operatorname{SINE} \mid \underline{\mathbf{A}} \mathrm{t})=$ & 148,074 \\
\hline P likely $(\mathrm{SINE})=$ & 0,793 & $\mathrm{P}$ Value $(\mathrm{SINE})=$ & 0,207 & & \\
\hline $\mathbf{p}(\mathbf{I M P})=$ & $\mathbf{0 , 9 7 7}$ & $\left.\mathrm{X}^{2}(\mathrm{IMP} \mid \mathrm{At})\right)=$ & 38,361 & $\mathbf{X}^{2}(\mathrm{IMP} \mid \underline{\mathrm{B}} \mathrm{t})=$ & 1,867 \\
\hline $\mathrm{P}$ likely $(\mathrm{IMP})=$ & 0,977 & $\mathrm{P}$ Value $(\mathrm{IMP})=$ & 0,023 & & \\
\hline$p\left(\operatorname{SINE}^{\wedge} \operatorname{IMP}\right)=$ & 0,745 & $\mathrm{X}^{2}\left(\mathrm{SINE}^{\wedge} \mathrm{IMP} \mid \mathrm{At}\right)=$ & 581,861 & $\mathrm{X}^{2}\left(\mathrm{SINE}^{\wedge} \mathrm{IMP} \mid \mathrm{Bt}\right)=$ & 581,861 \\
\hline p likely $\left(\right.$ SINE$\left.^{\wedge} \mathrm{IMP}\right)=$ & 0,775 & $\mathrm{p}$ Value $\left(\operatorname{SINE}^{\wedge} \mathrm{IMP}\right)=$ & 0,225 & & \\
\hline $\mathbf{p}(\mathbf{E X C L})=$ & 0,986 & $X^{2}(E X C L \mid A t)=$ & 13,361 & $\mathbf{X}^{2}(\mathbf{E X C L} \mid \mathrm{Bt})=$ & 1,994 \\
\hline$P($ Likely EXCL $)=$ & 0,986 & $P$ Value $(E X C L)=$ & 0,014 & & \\
\hline Odds $\operatorname{ratio}(\mathrm{OR})=$ & 1,857 & $95 \% \mathrm{CI}(\mathrm{OR}):$ & 1,218 & to & 2,831 \\
\hline
\end{tabular}

The relative frequency of the conditio per quam relationship between GS and NHL is $\mathrm{p}(\mathrm{IMP})=0,977$. The approximate $\mathrm{P}$ Value can be calculated as $\mathrm{P}$ Value $(\mathrm{IMP})=0,023$, which is significant. The significance of these data tested by the Chi-square goodness of fit test (sample size $n=2643$ ) yields the following results, while the $\mathrm{X}^{2}$ critical (degrees of freedom $=1$, Alpha 0,05) is $X^{2}($ critical $)=3,84145882$. Firstly. The same data demand that the calculated $\mathrm{X}^{2}(\mathrm{IMP} \mid \mathrm{At})$ is $\mathrm{X}^{2}(\mathrm{IMP} \mid \mathrm{At})=(((61$ )$\left.\left.^{*}(61)\right) / 97\right)+0=38,361$, a non-significant result. Secondly. The same data demand that the calculated $\mathrm{X}^{2}(\mathrm{IMP} \mid$ Not $\mathrm{Bt})$ is $\mathrm{X}^{2}(\mathrm{IMP} \mid \operatorname{Not} \mathrm{Bt})=(((61) *(61)) / 1993)+0=1,867$, a significant result . The data of the study of De Roos et al. support both: GS is a sufficient condition of NHL and the same data demand too that GS is not a sufficient condition of NHL which is a contradiction! The index of unfairness of this study with $\mathrm{p}(\mathrm{IOU})$ $=0,717$ is too high and indicates that the data of the study of De Roos et al. are not appropriate enough to be analyzed for a conditio sine qua non or for a conditio per quam relationship. In toto, the data of the study of De Roos et al. are biased. Theoretically, GS may be effective against NHL. In this case we expect a significant negative causal relationship $\mathrm{k}$ and a significant exclusion relationship. The relative frequency of the exclusion relationship between GS and NHL is p (EXCL) = 0,986. The approximate $\mathrm{P}$ Value can be calculated as $\mathrm{P}$ Value $(\mathrm{EXCL})=0,014$, a significant result. However, the significance of these data can be tested by the Chi-square goodness of fit test (sample size $\mathrm{n}=2643$ ) too and yields the following results while the $\mathrm{X}^{2}$ critical (degrees of freedom $=1$, Alpha 0,05$)$ is $\mathrm{X}^{2}($ critical) $=3,84145882$. Firstly. The data demand that the calculated $\mathrm{X}^{2}(\mathrm{EXCL} \mid \mathrm{At})$ is $\mathrm{X}^{2}(\mathrm{EXCL} \mid \mathrm{At})=\left(\left((36)^{*}(36)\right) / 97\right)+0=13,361$, a non-significant result. Secondly. The same data demand too that the calculated $\mathrm{X}^{2}(\mathrm{EXCL} \mid \mathrm{Bt})$ is $\mathrm{X}^{2}(\mathrm{EXCL} \mid \mathrm{Bt})=\left(\left((36)^{*}(36)\right) / 650\right)$ $+0=1,994$, a significant result. In point of fact, the data of the study of De Roos et al. support in the same respect both: GS 
excludes NHL and the same data demand too that GS does not exclude NHL which is a contradiction! As proofed before, the data demand that the hypothesis of a conditio sine qua non relationship or of a conditio per quam relationship must be rejected. However, the index of independence of the study of De Roos et al. ${ }^{51}$ is $\mathrm{p}(\mathrm{IOI})=0,209$ and appropriate enough to analyze the data for an exclusion relationship. And indeed, the data of the study of De Roos et al. do support the hypothesis that GS excludes NHL because the approximate $\mathrm{P}$ Value can be calculated as P Value $(\mathrm{EXCL})=0,014$, a significant result. Unfortunately, and besides of a $\mathrm{p}(\mathrm{IOI})=0,209$, such a conclusion is false or seriously misleading. Mathematically, a significant exclusion relationship demands at least a negative (and possibly significant) causal relationship $\mathrm{k}$ which is not given. The causal relationship $\mathrm{k}$ is $\mathrm{k}=+0,057$ and positive while the approximate $95 \%$ coincidence interval of the causal relationship $\mathrm{k}$ is between 0,013 and 0,100 . The one-sided right tailed $\mathrm{P}$ Value of the causal relationship $\mathrm{k}$ calculated according to the hypergeometric distribution is $\mathrm{P}$ Value $(\mathrm{k} \mid \mathrm{HGD})=0,00351$, a significant result. Therefore, the data of the study of De Roos et al. are biased and cannot be used to solve the problem of the relationship between GS and NHL. Formally, according to the data of De Roos et al. it is not possible to conclude that Glyphosate is at least a cause of Non-Hodgkin Lymphoma.

\section{Quod erat demonstrandum.}

Theorem 3.4. (Glyphosate is neither the cause nor a cause of Non-Hodgkin Lymphoma.)

De Roos et al. ${ }^{53}$ evaluated the associations between the exposure to the broad-spectrum herbicide Glyphosate and cancer incidence in a prospective cohort study of 57,311 applicators in the U.S.

\section{Claim.}

\section{Null Hypothesis:}

Glyphosate is neither the cause nor a cause of Non-Hodgkin Lymphoma. In other words, $\mathrm{k}=0$.

\section{Alternative Hypothesis:}

Glyphosate is either the cause or a cause of Non-Hodgkin Lymphoma. In other words, $\mathrm{k}>0$.

\section{Proof.}

De Roos et al. investigated the potential health effects of Glyphosate in humans with respect of the development of Non-Hodgkin Lymphoma. The data as obtained by De Roos et al. (De Roos et al., 2005) are view by table 7. The index of independence of the study of De Roos et al. ${ }^{53}$ is $\mathrm{p}(\mathrm{IOI})=0,754$. The data of the study of De Roos et al. are more or less of none value to be considered for the re-analysis of causal relationships $\mathrm{k}$ and for the re analysis of the exclusion relationship. The index of unfairness of this study is $\mathrm{p}(\mathrm{IOU})=0,243$ and indicates that the data are of some even if limited value to be analyzed for the existence of conditions or of risk factors. Altogether, the data as published by the study of De Roos et al. are more or less biased and can be considered only with very great care. The relative frequency of the conditio sine qua non relationship between GS and NHL is $\mathrm{p}(\mathrm{SINE})=0,999613$. The approximate $\mathrm{P}$ Value can be calculated as $\mathrm{P}$ Value $(\mathrm{SINE})=0,000387$, a highly significant result. Based on this test statistics, without GS no NHL. However, the significance of these data tested by the Chi-square goodness of fit test (sample size $n=54315$ ) yields the following results, while the $\mathrm{X}^{2}$ critical (degrees of freedom $=1$, Alpha 0,05) is $\mathrm{X}^{2}$ (critical) $=3,84145882$. Firstly. The data demand that the calculated $\mathrm{X}^{2}(\mathrm{SINE} \mid \mathrm{Bt})$ is $\mathrm{X}^{2}(\mathrm{SINE} \mid \mathrm{Bt})=$ $(((21) *(21)) / 92)+0=4,793$, a non-significant result. Secondly. The same data demand that the calculated $\mathrm{X}^{2}$ (SINE|Not At) is $\mathrm{X}^{2}(\mathrm{SINE} \mid$ Not At $)=(((21) *(21)) / 13280)+0=0,033$, a significant result. Thus far, the data of this study of De Roos et al. support both: GS is a necessary condition of NHL and the same data demand too that GS is not a necessary condition of NHL which is a contradiction! 
Table 7.

The study of De Roos et al., 2005.

\begin{tabular}{|c|c|c|c|c|}
\hline \multicolumn{2}{|l|}{$\begin{array}{l}\text { Country: } \\
\text { USA }\end{array}$} & $\begin{array}{c}\text { Non-H } \\
\text { YES }\end{array}$ & toma & \\
\hline \multirow{3}{*}{ Glyphosate } & YES & 71 & 40964 & 41035 \\
\hline & NO & 21 & 13259 & 13280 \\
\hline & & 92 & 54223 & 54315 \\
\hline
\end{tabular}

\begin{tabular}{|c|c|c|c|c|c|}
\hline \multicolumn{6}{|l|}{ Statistical analysis } \\
\hline Causal relationship $\mathrm{k}=$ & $+0,002$ & $95 \% \mathrm{CI}(\mathrm{k}):$ & $-0,008$ & to & 0,011 \\
\hline$P$ value $(k \mid H G D)=$ & 0,41236 & Chi Sq. $(k)=$ & 0,132 & & \\
\hline$p(I O I)=$ & 0,754 & $\mathbf{p}(\mathrm{IOU})=$ & 0,243 & $\mathbf{p}(\mathrm{IOU})+\mathbf{p}(\mathrm{IOI})=$ & 0,997 \\
\hline$p($ SINE $)=$ & 0,999613 & $\mathrm{X}^{2}(\mathrm{SINE} \mid \mathrm{Bt})=$ & 4,793 & $\mathrm{X}^{2}(\operatorname{SINE} \mid \underline{\mathbf{A}} \mathrm{t})=$ & $\mathbf{0 , 0 3 3}$ \\
\hline $\mathrm{P}$ likely $(\mathrm{SINE})=$ & 1,000 & $\mathrm{P}$ Value (SINE)= & 0,00039 & & \\
\hline $\mathbf{p}(\mathbf{I M P})=$ & 0,246 & $\left.\mathrm{X}^{2}(\mathrm{IMP} \mid \mathrm{At})\right)=$ & 40893,123 & $\mathrm{X}^{2}(\mathrm{IMP} \mid \underline{\mathrm{B}} \mathrm{t})=$ & 30947,187 \\
\hline $\mathrm{P}$ likely $(\mathrm{IMP})=$ & 0,470 & $\mathrm{P}$ Value $(\mathrm{IMP})=$ & 0,530 & & \\
\hline $\mathbf{p}\left(\mathrm{SINE}^{\wedge} \mathrm{IMP}\right)=$ & 0,245 & $\mathrm{X}^{2}\left(\mathrm{SINE}^{\wedge} \mathrm{IMP} \mid \mathrm{At}\right)=$ & 30951,980 & $\mathrm{X}^{2}\left(\mathrm{SINE}^{\wedge} \mathrm{IMP} \mid \mathrm{Bt}\right)=$ & 30951,980 \\
\hline $\mathrm{p}$ likely $\left(\mathrm{SINE}^{\wedge} \mathrm{IMP}\right)=$ & 0,470 & $\mathrm{p}$ Value $\left(\mathrm{SINE}^{\wedge} \mathrm{IMP}\right)=$ & 0,530 & & \\
\hline p $(\mathbf{E X C L})=$ & 0,999 & $\mathbf{X}^{2}(\mathbf{E X C L} \mid \mathbf{A t})=$ & 0,123 & $\mathrm{X}^{2}(\mathrm{EXCL} \mid \mathrm{Bt})=$ & 54,793 \\
\hline $\mathrm{P}($ Likely EXCL $)=$ & 0,999 & $P$ Value $(E X C L)=$ & 0,001306 & & \\
\hline Odds $\operatorname{ratio}(\mathrm{OR})=$ & 1,094 & $95 \% \mathrm{CI}(\mathrm{OR}):$ & 0,672 & to & 1,781 \\
\hline
\end{tabular}

This result cannot be considered as significant even if the causal relationship is positive. Whether a Chi-square goodness of fit test should be applied to such a sample size ( $\mathrm{n}=54315)$, is not the point of issue in this respect. The data this study of De Roos et al. are biased and not for sure of use for these purposes. The relative frequency of the conditio per quam relationship between GS and NHL is $\mathrm{p}(\mathrm{IMP})=0,246$. The approximate $\mathrm{P}$ Value can be calculated as $\mathrm{P}$ Value $(\mathrm{IMP})=0,530$, a non-significant result. In other words, the use or the contact with GS does not imply NHL. The significance of these data tested by the Chi-square goodness of fit test (sample size $n=54315$ ) yields the following result while the $\mathrm{X}^{2}$ critical (degrees of freedom $=1$, Alpha 0,05 ) is $\mathrm{X}^{2}$ (critical) $=3,84145882$. Firstly. The data of this study of De Roos et al. demand that the calculated $\mathrm{X}^{2}(\mathrm{IMP} \mid \mathrm{At})$ is $\mathrm{X}^{2}(\mathrm{IMP} \mid \mathrm{At})=$ $(((40964) *(40964)) / 41035)+0=40893,123$, a non-significant result. Secondly. The same data demand that the calculated
$\mathrm{X}^{2}(\mathrm{IMP} \mid$ Not Bt $)$ is $\mathrm{X}^{2}(\mathrm{IMP} \mid$ Not Bt $)=(((40964) *(40964)) / 54223)$ $+0=30947,187$, a non-significant result. The data of the study of De Roos et al. do not support the hypothesis that GS is a sufficient condition of NHL. However, it is necessary to obtain a significant sufficient condition to, to be able to establish a significant cause effect relationship. Contrary to expectation, the data of this study of De Roos et al. support the hypothesis too that GS protects against NHL. The relative frequency of the exclusion relationship between GS and NHL is $\mathrm{p}(\mathrm{EXCL})=0,999$. The approximate $\mathrm{P}$ Value can be calculated as $\mathrm{P}$ Value $(\mathrm{EXCL})=$ 0,001306. Thus far, as proofed before, without GS no NHL (P Value $(\mathrm{SINE})=0,00039)$ and equally GS excludes NHL (P Value $(E X C L)=0,001306)$ which is a contradiction. The data of this study of De Roos et al. are self-contradictory and of very limited value. In the same respect, the cause-effect relationship is not negative while the index of independence of the study of De 


\section{Ilija Barukčić}

Roos et al. ${ }^{53}$ is $\mathrm{p}(\mathrm{IOI})=0,754$ and far away from 0 . Therefore, the conclusion GS excludes NHL is not justified even if supported by the data. The significance of these data tested by the Chi-square goodness of fit test (sample size $\mathrm{n}=54315$ ) yields the following results, while the $\mathrm{X}^{2}$ critical (degrees of freedom $=1$, Alpha 0,05) is $\mathrm{X}^{2}$ (critical) $=3,84145882$. Firstly. The data demand that the calculated $\mathrm{X}^{2}$ (EXCL $\left.\mid \mathrm{At}\right)$ is $\mathrm{X}^{2}$ (EXCL $\left.\mid \mathrm{At}\right)=\left(\left(\left(\begin{array}{ll} & \end{array}\right) *(71)\right) /\right.$ $41035)+0=0,123$, a significant result. Secondly. The same data demand that the calculated $\mathrm{X}^{2}(\mathrm{EXCL} \mid \mathrm{Bt})$ is $\mathrm{X}^{2}(\mathrm{EXCL} \mid \mathrm{Bt})=$ $(((71) *(71)) / 92)+0=54,793$, a non-significant result. The data of the study of De Roos et al. support both: GS excludes NHL and the same data demand too that GS does not exclude NHL which is a contradiction! The data of the study of De Roos et al. are biased and cannot be used for these purposes. The causal relationship $\mathrm{k}$ is $\mathrm{k}=0,002$ and positive while the approximate 95\% coincidence interval of the causal relationship $\mathrm{k}$ is between $-0,008$ and 0,011 . The one-sided right tailed $P$ Value of the causal relationship $\mathrm{k}$ calculated according to the hypergeometric distribution is $\mathrm{P}$ Value $(\mathrm{k} \mid \mathrm{HGD})=0,41236$ and not significant. The data of De Roos et al., do not provide any valuable contribution with respect to the causal relationship between Glyphosate and Non-Hodgkin Lymphoma. The null-hypothesis cannot be rejected. There is no causal relationship between Glyphosate and Non-Hodgkin Lymphoma according to this data of De Roos et al. ${ }^{53}$.

\section{Quod erat demonstrandum.}

Theorem 3.5. (Glyphosate is neither the cause nor a cause of Non-Hodgkin Lymphoma.)

Eriksson et al. ${ }^{54}$ evaluated the associations between the exposure to the broad-spectrum herbicide Glyphosate and cancer incidence in a prospective cohort study of 57,311 applicators in the U.S.
Journal of Drug Delivery \& Therapeutics. 2020; 10(1-s):6-29

Claim.

\section{Null Hypothesis:}

Glyphosate is neither the cause nor a cause of Non-Hodgkin Lymphoma. In other words, $\mathrm{k}=0$.

\section{Alternative Hypothesis:}

Glyphosate is either the cause or a cause of Non-Hodgkin Lymphoma. In other words, $\mathrm{k}>0$.

\section{Proof.}

Eriksson et al. (Eriksson, Hardell, Carlberg, \& Akerman, 2008) investigated the potential health effects of Glyphosate in humans with respect of the development of Non-Hodgkin Lymphoma. The data as obtained by Eriksson et al. (Eriksson, Hardell, Carlberg, \& Akerman, 2008) are view by table 8

The index of independence of the study of Eriksson et al. ${ }^{54}$ is $\mathrm{p}(\mathrm{IOI})=0,448$ and is only of restricted value to consider these data for the re-analysis for causal relationship and for the re-analysis of the exclusion relationship. The index of unfairness of this study is $\mathrm{p}(\mathrm{IOU})=0,503$ and do indicate potentially biased data. Altogether, the data as published by the study of Eriksson et al. are potentially biased. The relative frequency of the conditio sine qua non relationship between GS and NHL is $p($ SINE $)=$ 0,542575. The approximate $P$ Value can be calculated as $P$ Value $(\mathrm{SINE})=0,367089$. The significance of these data tested by the Chi-square goodness of fit test (sample size $n=1926$ ) yields the following results while the $\mathrm{X}^{2}$ critical (degrees of freedom $=1$, Alpha 0,05) is $\mathrm{X}^{2}$ (critical) $=3,84145882$. Firstly. The data demand that the calculated $\mathrm{X}^{2}(\mathrm{SINE} \mid \mathrm{Bt})$ is $\mathrm{X}^{2}(\mathrm{SINE} \mid \mathrm{Bt})=$ $(((881) *(881)) / 910)+0=852,924$. Secondly. The same data demand that the calculated $\mathrm{X}^{2}$ (SINE|Not At) is $\mathrm{X}^{2}$ (SINE|Not At) $=(((881) *(881)) / 1879)+0=413,071$ while the causal relationship is positive. 
Table 8.

The study of Eriksson et al., 2008.

\begin{tabular}{|c|c|c|c|c|}
\hline $\begin{array}{l}\text { Country: } \\
\text { Sweden }\end{array}$ & & $\begin{array}{c}\text { Non-Hod } \\
\text { YES }\end{array}$ & NO & \\
\hline \multirow{3}{*}{ Glyphosate } & YES & 29 & 18 & 47 \\
\hline & $\mathrm{NO}$ & 881 & 998 & 1879 \\
\hline & & 910 & 1016 & 1926 \\
\hline
\end{tabular}

\begin{tabular}{|c|c|c|c|c|c|}
\hline \multicolumn{6}{|l|}{ Statistical analysis } \\
\hline Causal relationship $\mathrm{k}=$ & $+0,046$ & $95 \% \mathrm{CI}(\mathrm{k}):$ & $-0,005$ & to & 0,097 \\
\hline$P$ value $(k \mid H G D)=$ & 0,03123 & Chi Sq. $(\mathrm{k})=$ & 4,038 & & \\
\hline$p(I O I)=$ & 0,448 & $p(I O U)=$ & $\mathbf{0 , 5 0 3}$ & $\mathbf{p}(\mathrm{IOU})+\mathbf{p}(\mathrm{IOI})=$ & 0,951 \\
\hline$p($ SINE $)=$ & $\mathbf{0 , 5 4 3}$ & $\mathrm{X}^{2}(\mathrm{SINE} \mid \mathrm{Bt})=$ & 852,924 & $\mathrm{X}^{2}(\mathrm{SINE} \mid \underline{\mathrm{A}} \mathrm{t})=$ & 413,071 \\
\hline P likely $(\mathrm{SINE})=$ & 0,633 & $P$ Value $(\mathrm{SINE})=$ & 0,367 & & \\
\hline $\mathbf{p}(\mathbf{I M P})=$ & 0,991 & $\left.\mathrm{X}^{2}(\mathrm{IMP} \mid \mathrm{At})\right)=$ & 6,894 & $\mathbf{X}^{2}(\mathbf{I M P} \mid \underline{\mathbf{B}} \mathrm{t})=$ & 0,319 \\
\hline $\mathrm{P}$ likely $(\mathrm{IMP})=$ & 0,991 & P Value $($ IMP) $=$ & 0,009 & & \\
\hline $\mathrm{p}\left(\mathrm{SINE}^{\wedge} \mathrm{IMP}\right)=$ & $\mathbf{0 , 5 3 3}$ & $\mathrm{X}^{2}\left(\mathrm{SINE}^{\wedge} \mathrm{IMP} \mid \mathrm{At}\right)=$ & 853,243 & $\mathrm{X}^{2}\left(\mathrm{SINE}^{\wedge} \mathrm{IMP} \mid \mathrm{Bt}\right)=$ & 853,243 \\
\hline p likely $\left(\operatorname{SINE}^{\wedge} \mathrm{IMP}\right)=$ & 0,627 & $\mathrm{p}$ Value $\left(\mathrm{SINE}^{\wedge} \mathrm{IMP}\right)=$ & 0,373 & & \\
\hline$p($ EXCL $)=$ & 0,985 & $X^{2}(E X C L \mid A t)=$ & 17,894 & $\mathbf{X}^{2}(\mathbf{E X C L} \mid \mathbf{B t})=$ & 0,924 \\
\hline $\mathrm{P}($ Likely EXCL $)=$ & 0,985 & P Value $(\mathrm{EXCL})=$ & 0,015 & & \\
\hline Odds $\operatorname{ratio}(\mathrm{OR})=$ & 1,825 & $95 \% \mathrm{CI}(\mathrm{OR}):$ & 1,007 & to & 3,309 \\
\hline
\end{tabular}

The index of independence of the study of Eriksson et al. ${ }^{54}$ is $p(I O I)=0,448$. The data of the study of Eriksson et al. are more or less of none value to be considered for the re-analysis for causal relationships or for the re-analysis of the exclusion relationship. The index of unfairness of this study is $\mathrm{p}(\mathrm{IOU})=0,503$ and do indicate biased data too. Altogether, the data as published by the study of Eriksson et al. are biased. The relative frequency of the conditio sine qua non relationship between GS and NHL is $p$ $(\mathrm{SINE})=0,542575$. The approximate $\mathrm{P}$ Value can be calculated as $\mathrm{P}$ Value $(\mathrm{SINE})=0,367089$. The significance of these data tested by the Chi-square goodness of fit test (sample size $\mathrm{n}=$ 1926) yields the following results while the $X^{2}$ critical (degrees of freedom $=1$, Alpha 0,05) is $\mathrm{X}^{2}($ critical $)=3,84145882$. Firstly. The data demand that the calculated $\mathrm{X}^{2}(\mathrm{SINE} \mid \mathrm{Bt})$ is $\mathrm{X}^{2}(\mathrm{SINE} \mid \mathrm{Bt})$ $=(((881) *(881)) / 910)+0=852,924$. Secondly. The same data demand that the calculated $\mathrm{X}^{2}(\mathrm{SINE} \mid \mathrm{Not} A t)$ is $\mathrm{X}^{2}(\mathrm{SINE} \mid \mathrm{Not} A t)$ $=\left(\left((881)^{*}(881)\right) / 1879\right)+0=413,071$ while the causal relationship is positive. Mathematically, it is problematic if the causal relationship is positive and significant while the conditio sine qua non relationship is not significant. The relative frequency of the conditio per quam relationship between GS and NHL is $\mathrm{p}(\mathrm{IMP})=0,991$. The approximate $\mathrm{P}$ Value can be calculated as $\mathrm{P}$ Value $(\mathrm{IMP})=0,009$, a significant result. In other words, if contact with GS then NHL. However, the significance of these data tested by the Chi-square goodness of fit test (sample size $\mathrm{n}=1926$ ) too and yields the following results, while the $\mathrm{X}^{2}$ critical $($ degrees of freedom $=1$, Alpha 0,05$)$ is $X^{2}$ (critical $)=$ 3,84145882. Firstly. The data demand that the calculated $\mathrm{X}^{2}(\operatorname{IMP} \mid \mathrm{At})$ is $\mathrm{X}^{2}(\mathrm{IMP} \mid \mathrm{At})=(((18) *(18)) / 47)+0=6,894$, a non-significant result. Secondly. The same data demand too that the calculated $\mathrm{X}^{2}(\mathrm{IMP} \mid \mathrm{Not} \mathrm{Bt})$ is $\mathrm{X}^{2}(\mathrm{IMP} \mid \mathrm{Not} \mathrm{Bt})=$ $(((18) *(18)) / 1016)+0=0,319$, a significant result. The data of the study of Eriksson et al. support both: GS is a sufficient condition of NHL and the same data demand too that GS is not a 
sufficient condition of NHL which is a contradiction! Furthermore, mathematically a significant positive causal relationship demands additionally at least a significant conditio per quam relationship or a significant conditio sine qua non relationship or at best both. Thus far, the data of the study of Eriksson et al. are self-contradictory and biased and cannot be used for our purposes. Again, and contrary to expectation, theoretically the use of GS can have protective effects against NHL. In this case we expect a significant negative causal relationship $\mathrm{k}$ which is not given and a significant exclusion relationship. The relative frequency of the exclusion relationship between GS and NHL is $\mathrm{p}(\mathrm{EXCL})=0,985$. The approximate $\mathrm{P}$ Value can be calculated as $\mathrm{P}$ Value $(\mathrm{EXCL})=$ 0,015 , a significant result. The significance of these data tested by the Chi-square goodness of fit test (sample size $n=1926$ ) yields the following results, while the $\mathrm{X}^{2}$ critical (degrees of freedom $=$ 1, Alpha 0,05) is $\mathrm{X}^{2}$ (critical) $=3,84145882$. Firstly. The data demand that the calculated $\mathrm{X}^{2}(\mathrm{EXCL} \mid \mathrm{At})$ is $\mathrm{X}^{2}$ (EXCL $\left.\mid \mathrm{At}\right)=$ $(((29) *(29)) / 47)+0=17,894$. Secondly. The same data demand too that the calculated $\mathrm{X}^{2}(\mathrm{EXCL} \mid \mathrm{Bt})$ is $\mathrm{X}^{2}(\mathrm{EXCL} \mid \mathrm{Bt})=$ $(((29) *(29)) / 910)+0=0,924$, a significant result while the sample size of $n=1926$ allows the use of the Chi-square distribution. The data of the study of Eriksson et al. support both:

GS excludes NHL and the same data demand too that GS does not exclude NHL which is a contradiction! The data of the study of Eriksson et al. are biased and cannot be used for these purposes as already indicated by an is $\mathrm{p}(\mathrm{IOI})=0,448$. The causal relationship $\mathrm{k}$ is $\mathrm{k}=0,046$ and positive while the approximate $95 \%$ coincidence interval of the causal relationship $\mathrm{k}$ is between $-0,005$ and 0,097 . The one-sided right tailed $\mathrm{P}$ Value of the causal relationship $\mathrm{k}$ calculated according to the hypergeometric distribution is $\mathrm{P}$ Value $(\mathrm{k} \mid \mathrm{HGD})=0,03123$ and significant but of no use. The data of the study of Eriksson et al. are biased. In other words, Glyphosate is neither a necessary condition nor a sufficient condition for the development of Non-Hodgkin Lymphoma. Furthermore, the data of Eriksson et al. were not able to provide any reasonable evidence that GS is either the cause or a cause of Non-Hodgkin Lymphoma.

\section{Quod erat demonstrandum.}

Theorem 3.6. (Glyphosate is neither the cause nor a cause of Non-Hodgkin Lymphoma.)

Orsi et al. ${ }^{55}$ conducted a hospital-based case-control study in France between 2000 and 2004 to investigate the relationship between occupational exposure to pesticides and the risk of lymphoid neoplasms in men.

\section{Claim.}

\section{Null Hypothesis:}

Glyphosate is neither the cause nor a cause of Non-Hodgkin Lymphoma. In other words, $\mathrm{k}=0$.

\section{Alternative Hypothesis:}

Glyphosate is either the cause or a cause of Non-Hodgkin Lymphoma. In other words, $\mathrm{k}>0$.

\section{Proof.}

The study of Orsi et al. (Orsi et al., 2009) investigated the potential health effects of Glyphosate in humans with respect of the development of Non-Hodgkin Lymphoma. The data as obtained by Orsi et al. (Orsi et al., 2009) are view by table 9. 
Table 9.

The study of Orsi et al., 2009.

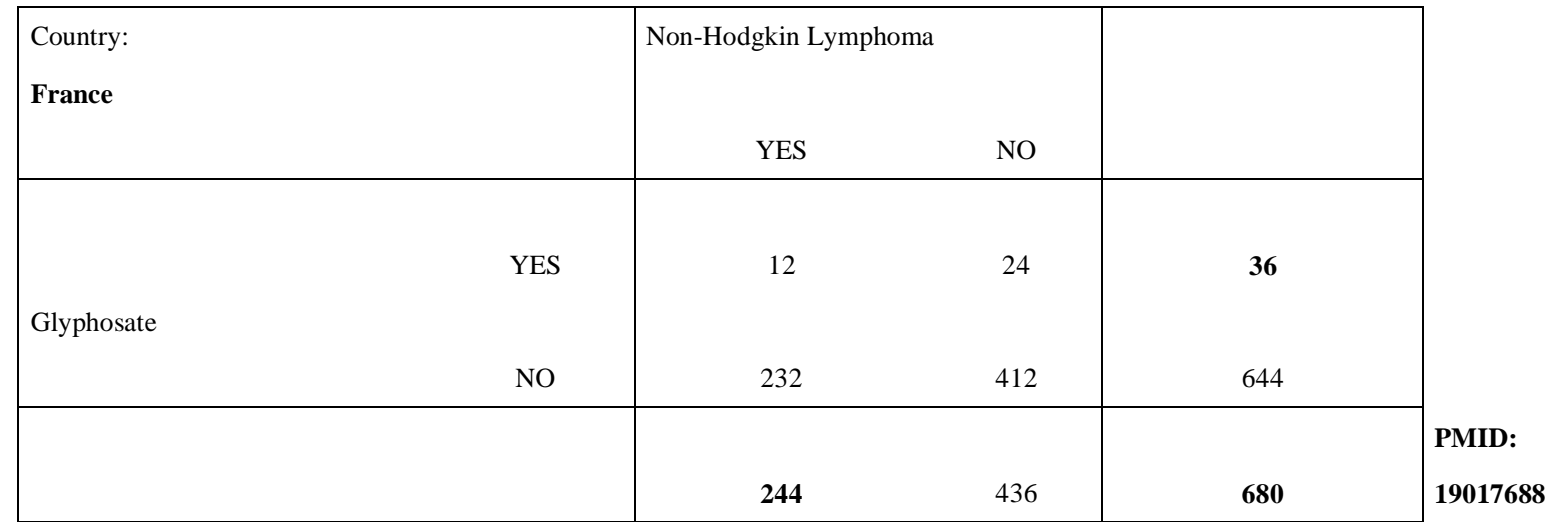

\begin{tabular}{|c|c|c|c|c|c|}
\hline \multicolumn{6}{|l|}{ Statistical analysis } \\
\hline Causal relationship $\mathrm{k}=$ & $-0,013$ & $95 \% \mathrm{CI}(\mathrm{k}):$ & $-0,098$ & to & 0,073 \\
\hline$P$ value $(k \mid H G D)=$ & 0,68930 & Chi Sq. $\cdot(k)=$ & 0,107 & & \\
\hline $\mathbf{p}(\mathbf{I O I})=$ & 0,306 & $\mathrm{p}(\mathrm{IOU})=$ & 0,588 & $\mathbf{p}(\mathrm{IOU})+\mathbf{p}(\mathrm{IOI})=$ & 0,894 \\
\hline$p($ SINE $)=$ & 0,659 & $\mathrm{X}^{2}(\mathrm{SINE} \mid \mathrm{Bt})=$ & 220,590 & $\mathrm{X}^{2}(\mathrm{SINE} \mid \underline{\mathrm{A}} \mathrm{t})=$ & 83,578 \\
\hline P likely $($ SINE $)=$ & 0,711 & $\mathrm{P}$ Value $(\mathrm{SINE})=$ & 0,289 & & \\
\hline $\mathbf{p}(\mathbf{I M P})=$ & 0,965 & $\left.\mathrm{X}^{2}(\mathrm{IMP} \mid \mathrm{At})\right)=$ & 16,000 & $\mathrm{X}^{2}(\mathrm{IMP} \mid \underline{\mathrm{B}} \mathrm{t})=$ & 1,321 \\
\hline $\mathrm{P}$ likely $(\mathrm{IMP})=$ & 0,965 & $\mathrm{P}$ Value $(\mathrm{IMP})=$ & 0,035 & & \\
\hline$p\left(\operatorname{SINE}^{\wedge} \operatorname{IMP}\right)=$ & 0,624 & $\mathrm{X}^{2}\left(\mathrm{SINE}^{\wedge} \mathrm{IMP} \mid \mathrm{At}\right)=$ & 221,911 & $\mathrm{X}^{2}\left(\mathrm{SINE}^{\wedge} \mathrm{IMP} \mid \mathrm{Bt}\right)=$ & 221,911 \\
\hline $\mathrm{p}$ likely $\left(\mathrm{SINE}^{\wedge} \mathrm{IMP}\right)=$ & 0,686 & $\mathrm{p}$ Value $\left(\mathrm{SINE}^{\wedge} \mathrm{IMP}\right)=$ & 0,314 & & \\
\hline $\mathbf{p}(\mathbf{E X C L})=$ & 0,982 & $\mathrm{X}^{2}(\mathrm{EXCL} \mid \mathrm{At})=$ & 4,000 & $\mathrm{X}^{2}(\mathrm{EXCL} \mid \mathrm{Bt})=$ & 0,590 \\
\hline$P($ Likely EXCL $)=$ & 0,983 & $P$ Value $(E X C L)=$ & 0,017 & & \\
\hline Odds $\operatorname{ratio}(\mathrm{OR})=$ & 0,888 & $95 \% \mathrm{CI}(\mathrm{OR}):$ & 0,436 & to & 1,809 \\
\hline
\end{tabular}

The index of independence of the study of Orsi et al. ${ }^{55}$ is $\mathrm{p}(\mathrm{IOI})=$ 0,306 and is of some and equally restricted value to consider these data for the re-analysis of causal relationships and for the re-analysis of the exclusion relationship. The index of unfairness of this study is $\mathrm{p}(\mathrm{IOU})=0,588$ and indicate to some extent potentially biased data. Altogether, the data as published by the study of Orsi et al. are more or less biased. The relative frequency of the conditio sine qua non relationship between GS and NHL is $\mathrm{p}(\mathrm{SINE})=0,658824$. The approximate $\mathrm{P}$ Value can be calculated as $\mathrm{P}$ Value $(\mathrm{SINE})=0,289067$. The significance of these data tested by the Chi-square goodness of fit test (sample size $n=680$ ) yields the following results, while the $X^{2}$ critical $($ degrees of freedom $=1$, Alpha 0,05$)$ is $\mathrm{X}^{2}$ (critical) $=$ 3,84145882. Firstly. The data demand that the calculated $\mathrm{X}^{2}(\mathrm{SINE} \mid \mathrm{Bt})$ is $\mathrm{X}^{2}(\mathrm{SINE} \mid \mathrm{Bt})=(((232) *(232)) / 244)+0=$ 220,590. Secondly. The same data demand that the calculated $\mathrm{X}^{2}(\mathrm{SINE} \mid$ Not At $)$ is $\mathrm{X}^{2}(\mathrm{SINE} \mid \mathrm{Not} \mathrm{At})=(((232) *(232)) / 644)+0=$
83,578. The data of the study of Orsi et al. do not support the hypothesis that GS is a necessary condition of NHL! Furthermore, mathematically a negative causal relationship, even if not significant, is not under any circumstances in accordance with the possibility of a conditio sine qua non relationship. The relative frequency of the conditio per quam relationship between GS and NHL is $p($ IMP) $=0,965$. The approximate $\mathrm{P}$ Value can be calculated as $\mathrm{P}$ Value (IMP) $=0,035$, a significant result. However, mathematically a negative causal relationship, even if not significant, is not under any circumstances in accordance with the possibility of a conditio per quam relationship. The significance of these data tested by the Chi-square goodness of fit test (sample size $n=680$ ) yields the following results while the $\mathrm{X}^{2}$ critical (degrees of freedom $=1$, Alpha 0,05$)$ is $\mathrm{X}^{2}$ (critical) $=3,84145882$. Firstly. The data demand that the calculated $\mathrm{X}^{2}(\mathrm{IMP} \mid \mathrm{At})$ is $\mathrm{X}^{2}(\mathrm{IMP} \mid \mathrm{At})=$ $(((24) *(24)) / 36)+0=16,000$, a non-significant result. 


\section{Ilija Barukčić}

Secondly. The same data demand that the calculated X2(IMP|Not $\mathrm{Bt})$ is $\mathrm{X}^{2}(\mathrm{IMP} \mid \operatorname{Not} \mathrm{Bt})=\left(\left((24)^{*}(24)\right) / 436\right)+0=1,321$, a significant result. The data of the study of Orsi et al. support both: GS is a sufficient condition of NHL and the same data demand too that GS is not a sufficient condition of NHL which is a contradiction! Here too it should be stressed again that mathematically a negative causal relationship, even if not significant, contradicts under these circumstances the possibility of a conditio per quam relationship. The data of the study of Orsi et al. are self-contradictory, biased and cannot be used for sure for our purposes. It was with dismay that the data of the study of Orsi et al. support the hypothesis that the use of GS has protective effects against NHL. In this case we expect a negative causal relationship $\mathbf{k}$ which is given and a significant exclusion relationship which is given too. The relative frequency of the exclusion relationship between GS and NHL is $\mathrm{p}(\mathrm{EXCL})=$ 0,982. The approximate $\mathrm{P}$ Value can be calculated as $\mathrm{P}$ Value $(\mathrm{EXCL})=0,017$, a significant result. The significance of these data tested by the Chi-square goodness of fit test (sample size $n$ $=680$ ) yields the following results while the $\mathrm{X}^{2}$ critical (degrees of freedom $=1$, Alpha 0,05) is $\mathrm{X}^{2}($ critical $)=3,84145882$. Firstly. The data demand that the calculated $\mathrm{X}^{2}(\mathrm{EXCL} \mid \mathrm{At})$ is $\mathrm{X}^{2}(\mathrm{EXCL} \mid \mathrm{At})=(((12) *(12)) / 36)+0=4,000$, a non-significant result. Secondly. The same data demand too that the calculated $\mathrm{X}^{2}(\mathrm{EXCL} \mid \mathrm{Bt})$ is $\mathrm{X}^{2}(\mathrm{EXCL} \mid \mathrm{Bt})=(((12) *(12)) / 244)+0=0,590$, a significant result. In point of fact, the data of the study of Orsi et al. support the hypothesis that both: GS excludes NHL and the same data demand too that GS do not exclude NHL which is a contradiction while the use of the Chi-square distribution was justified (sample size $n=680$ )! Even if the data of the study of Orsi et al. provide some evidence that GS excludes NHL such a conclusion is not justified, the data are potentially biased and cannot be used for these purposes. The causal relationship $\mathrm{k}$ is $\mathbf{k}=$ $\mathbf{- 0 , 0 1 3}$ and negative while the approximate $95 \%$ coincidence interval of the causal relationship $\mathrm{k}$ is between $-0,098$ and 0,073 .
Journal of Drug Delivery \& Therapeutics. 2020; 10(1-s):6-29

The one-sided right tailed $\mathrm{P}$ Value of the causal relationship $\mathrm{k}$ calculated according to the hypergeometric distribution is $\mathrm{P}$ Value $(\mathrm{k} \mid \mathrm{HGD})=0,68930$ and not significant. As long as we rely on the data of the study of Orsi et al. we just cannot decide what is true and what is false. In other words, according to the data of Orsi et al. Glyphosate is neither a necessary condition of Non-Hodgkin Lymphoma nor a sufficient condition of Non-Hodgkin Lymphoma. Furthermore, it is not for sure that GS excludes NHL besides of the P Value $(E X C L)=0,017$. Thus far, according to the data of Orsi et al., Glyphosate and Non-Hodgkin Lymphoma are not causally related.

\section{Quod erat demonstrandum.}

Theorem 3.7. (Glyphosate is neither the cause nor a cause of Non-Hodgkin Lymphoma.)

In the large, prospective cohort study of Andreotti et al. ${ }^{56}$ the previous (De Roos et al., 2005) evaluation of Glyphosate with cancer incidence was updated and again no association was apparent between Glyphosate and any solid tumors including NHL and its subtypes.

Claim.

\section{Null Hypothesis:}

Glyphosate is neither the cause nor a cause of Non-Hodgkin Lymphoma. In other words, $\mathrm{k}=0$.

\section{Alternative Hypothesis:}

Glyphosate is either the cause or a cause of Non-Hodgkin Lymphoma. In other words, $\mathrm{k}>0$.

Proof.

The study of Andreotti et al. investigated the potential health effects of Glyphosate in humans with respect of the development of Non-Hodgkin Lymphoma. The data as obtained by De Roos et al. (De Roos et al., 2005) are view by table $\mathbf{1 0}$ 
Table 10.

The study of Andreotti et al., 2018.

\begin{tabular}{|c|c|c|c|c|}
\hline \multicolumn{2}{|l|}{$\begin{array}{l}\text { Country: } \\
\text { USA }\end{array}$} & \multicolumn{2}{|c|}{ Non-Hodgkin Lymphoma } & \\
\hline \multirow{3}{*}{ Glyphosate } & YES & 440 & 43952 & 44392 \\
\hline & NO & 135 & 9724 & 9859 \\
\hline & & 575 & 53676 & 54251 \\
\hline
\end{tabular}

\begin{tabular}{|c|c|c|c|c|c|}
\hline Causal relationship $\mathrm{k}=$ & $-0,014$ & $95 \% \mathrm{CI}(\mathrm{k}):$ & $-0,024$ & to & $-0,005$ \\
\hline$P$ value $(k \mid$ HGD $)=$ & 0,99946 & Chi Sq. $\cdot(k)=$ & 11,000 & & \\
\hline$p(I O I)=$ & $\mathbf{0 , 8 0 8}$ & $p(I O U)=$ & 0,171 & $\mathbf{p}(\mathrm{IOU})+\mathbf{p}(\mathrm{IOI})=$ & 0,979 \\
\hline$p($ SINE $)=$ & 0,998 & $\mathrm{X}^{2}(\mathrm{SINE} \mid \mathrm{Bt})=$ & 31,696 & $\mathbf{X}^{2}(\operatorname{SINE} \mid \underline{\mathbf{A}} \mathrm{t})=$ & 1,849 \\
\hline $\mathrm{P}$ likely $(\mathrm{SINE})=$ & 0,998 & $\mathrm{P}$ Value (SINE) $=$ & 0,002 & & \\
\hline $\mathbf{p}(\mathbf{I M P})=$ & 0,190 & $\left.\mathbf{X}^{2}(\operatorname{IMP} \mid \mathbf{A t})\right)=$ & 43516,361 & $X^{2}(\operatorname{IMP} \mid \underline{B} t)=$ & 35989,610 \\
\hline $\mathrm{P}$ likely $(\mathrm{IMP})=$ & 0,445 & $\mathrm{P}$ Value $(\mathrm{IMP})=$ & 0,555 & & \\
\hline$p\left(\mathrm{SINE}^{\wedge} \mathrm{IMP}\right)=$ & 0,187 & $\mathrm{X}^{2}\left(\mathrm{SINE}^{\wedge} \mathrm{IMP} \mid \mathrm{At}\right)=$ & 36021,306 & $\mathrm{X}^{2}\left(\mathrm{SINE}^{\wedge} \mathrm{IMP} \mid \mathrm{Bt}\right)=$ & 36021,306 \\
\hline p likely $\left(\operatorname{SINE}^{\wedge} \mathrm{IMP}\right)=$ & 0,444 & $\mathrm{p}$ Value $\left(\mathrm{SINE}^{\wedge} \mathrm{IMP}\right)=$ & 0,556 & & \\
\hline p $($ EXCL $)=$ & 0,992 & $\mathrm{X}^{2}(\mathrm{EXCL} \mid \mathrm{At})=$ & 4,361 & $\mathrm{X}^{2}(\mathrm{EXCL} \mid \mathrm{Bt})=$ & 336,696 \\
\hline $\mathrm{P}($ Likely EXCL $)=$ & 0,992 & $P$ Value $(E X C L)=$ & 0,008 & & \\
\hline Odds ratio $(\mathrm{OR})=$ & 0,721 & $95 \% \mathrm{CI}(\mathrm{OR})$ & 0,594 & to & 0,876 \\
\hline
\end{tabular}

The index of independence of the study of Andreotti et al. ${ }^{56}$ is $p(I O I)=0,808$ with the consequence that the data of this study of Andreotti et al. are more or less of none value to be considered for the re-analysis of causal relationships or for the re-analysis of the exclusion relationship. The index of unfairness of this study is $\mathrm{p}(\mathrm{IOU})=0,171$ and allows to some extent to analyze the data for risk factors or conditions. Altogether, the data as published by the study of Andreotti et al. are more or less biased. The relative frequency of the conditio sine qua non relationship between GS and NHL is very impressive with $\mathrm{p}(\mathrm{SINE})=0,997512$. The approximate $\mathrm{P}$ Value can be calculated as $\mathrm{P}$ Value (SINE) = 0,002485 , a significant result. In other words, according to the study of Andreotti et al. without GS no NHL, while the cause effect relationship $\mathrm{k}$ is negative! However, mathematically a negative causal relationship regardless of whether significant or not is not in accordance with the possibility of significant a conditio sine qua non relationship. Thus far, these data are more or less self-contradictory. The significance of these data tested by the Chi-square goodness of fit test (sample size $n=54251$ ) yields the following result while the $\mathrm{X}^{2}$ critical (degrees of freedom $=1$, Alpha 0,05) is $\mathrm{X}^{2}$ (critical) $=3,84145882$. Firstly. The data demand that the calculated $\mathrm{X}^{2}(\mathrm{SINE} \mid \mathrm{Bt})$ is $\mathrm{X}^{2}(\mathrm{SINE} \mid \mathrm{Bt})=$ $(((135) *(135)) / 575)+0=31,696$, a non-significant result. Secondly. The same data demand too that the calculated $\mathrm{X}^{2}(\mathrm{SINE} \mid$ Not At $)$ is $\mathrm{X}^{2}(\mathrm{SINE} \mid \operatorname{Not} \mathrm{At})=(((135) *(135)) / 9859)+0$ $=1,849$, a significant result. It may well be that an $\mathrm{p}(\mathrm{IOU})=0,171$ allows to some restricted extent to analyze the data for a conditio sine qua none relationship, still, the data are self-contradictory. The data of the study of Andreotti et al. support both: GS is a necessary condition of NHL and the same data demand too that GS is not a necessary condition of NHL which is a contradiction! Furthermore, mathematically a negative causal relationship, even if not significant, is not compatible with the hypothesis of a conditio sine qua non relationship. The data of the 


\section{Ilija Barukčić}

study of Andreotti et al. are biased and of no use for these purposes. The relative frequency of the conditio per quam relationship between GS and NHL is $\mathrm{p}(\mathrm{IMP})=0,190$. The approximate $\mathrm{P}$ Value can be calculated as $\mathrm{P}$ Value (IMP) $=0,555$, a non-significant result. The significance of these data tested by the Chi-square goodness of fit test (sample size $n=54251$ ) yields the following results while the $\mathrm{X}^{2}$ critical (degrees of freedom $=1$, Alpha 0,05$)$ is $\mathrm{X}^{2}$ (critical) $=3,84145882$. Firstly. The data demand that the calculated $\mathrm{X}^{2}(\mathrm{IMP} \mid \mathrm{At})$ is $\mathrm{X}^{2}(\mathrm{IMP} \mid \mathrm{At})=$ $(((43952) *(43952)) / 44392)+0=43516,361$, a non-significant result. Secondly. The same data demand that the calculated $\mathrm{X}^{2}(\mathrm{IMP} \mid \mathrm{Not} \mathrm{Bt})$ is $\mathrm{X}^{2}(\mathrm{IMP} \mid \mathrm{Not} \mathrm{Bt})=(((43952) *(43952)) / 53676)$ $+0=35989,610$, a non-significant result. The data of the study of Andreotti et al. do not support the hypothesis that GS is a sufficient condition of NHL. However, mathematically a negative causal relationship and a $\mathrm{p}(\mathrm{IOI})=0,808$ suggest that the data are without any value for these purposes. The data of the study of Andreotti et al. are biased. Contrary to expectation, following the data of the study of Andreotti et al. ${ }^{56}$ we must conclude that GS is an antidot against NHL. In this case we expect a negative causal relationship $k$ and $a$ significant exclusion relationship and indeed both is given. The relative frequency of the exclusion relationship between GS and NHL is $\mathrm{p}(\mathrm{EXCL})=0,992$. The approximate $\mathrm{P}$ Value can be calculated as $\mathrm{P}$ Value $(\mathrm{EXCL})=0,008$. The significance of these data tested by the Chi-square goodness of fit test (sample size $n=54251$ ) yields the following results while the $\mathrm{X}^{2}$ critical (degrees of freedom $=1$, Alpha 0,05) is $\mathrm{X}^{2}$ (critical) $=3,84145882$. Firstly. The data demand that the calculated $\mathrm{X}^{2}$ (EXCL|At) is $\mathrm{X}^{2}(\mathrm{EXCL} \mid \mathrm{At})=(((440) *(440)) / 44392)+0=4,361, \mathrm{a}$ non-significant result. Secondly. The same data demand too that the calculated $\mathrm{X}^{2}(\mathrm{EXCL} \mid \mathrm{Bt})$ is $\mathrm{X}^{2}(\mathrm{EXCL} \mid \mathrm{Bt})=$ $(((440) *(440)) / 575)+0=336,696$, a non-significant result. Based on the Chi-square distribution, the data of the study of Andreotti et al. do not support the hypothesis that GS excludes NHL which is a contradiction. The causal relationship $\mathrm{k}$ is $\mathrm{k}=$ $-0,014$ and negative, while the approximate $95 \%$ coincidence interval of the causal relationship $\mathrm{k}$ is between $-0,024$ and $-0,005$. The one-sided right tailed $\mathrm{P}$ Value of the causal relationship $\mathrm{k}$ calculated according to the hypergeometric distribution is $\mathrm{P}$ Value $(\mathrm{k} \mid \mathrm{HGD})=0,99946$ and not significant. Thus far and formally the conclusion is not imperative that GS protects against NHL. However, a conclusion that GS protects against NHL is fallacious and not justified at all because of other reasons too.

Firstly. The index of unfairness of this study is $\mathrm{p}(\mathrm{IOU})=0,171$ ISSN: 2250-1177
Journal of Drug Delivery \& Therapeutics. 2020; 10(1-s):6-29

and even if very low does not guarantee that the data are of any use when analyzed for an exclusion relationship. Secondly. To rely on the data when analyzing the same for an exclusion relationship we need a very low $\mathrm{p}(\mathrm{IOI})$, if possible, a $\mathrm{p}(\mathrm{IOI})$ equal to zero, which is not given. The index of independence of the study of Andreotti et al. ${ }^{56}$ is $\mathrm{p}(\mathrm{IOI})=0,808$ with the consequence that it does not make any sense to consider a causal relationship between GS and NHL. The data of the study of Andreotti et al. are biased and do not provide anything valuable on the causal relationship between GS and NHL. In other words, according to the data of Andreotti et al. Glyphosate is neither a necessary condition of Non-Hodgkin Lymphoma nor a sufficient condition of Non-Hodgkin Lymphoma. Furthermore, the Null-hypothesis above must be rejected. According to the data of Andreotti et al., there is no significant positive causal relationship between the use of Glyphosate and Non-Hodgkin Lymphoma $(k=-0,014)$.

\section{Quod erat demonstrandum.}

Theorem 3.8. (Without Epstein-Barr virus infection no Non-Hodgkin Lymphoma.)

Non-Hodgkin lymphomas differ in several aspects but share some features too. Epstein-Barr virus (EBV) is possibly one of these common features and has been discussed ${ }^{57}$ as a cause of non-Hodgkin lymphoma (NHL). However, the role of EBV in non-Hodgkin lymphomas (NHLs) remains unclear. Teras et al. ${ }^{58}$ examined the association between prospectively-collected plasma EBV antibodies and NHL risk in the Cancer Prevention Study-II (CPS-II) Nutrition Cohort which included 225 NHL cases and 2:1 matched controls and documented an association between EBV serostatus or antibody levels (early antigen) and risk of the three most common types of NHL (diffuse large B-cell lymphoma, follicular lymphoma, chronic lymphocytic leukemia/small lymphocytic lymphoma).

\section{Claim.}

\section{Null Hypothesis:}

Epstein-Barr virus infection is a necessary condition of Non-Hodgkin Lymphoma.

In other words, without an Epstein-Barr virus infection no Non-Hodgkin Lymphoma.

\section{Alternative Hypothesis:}

Epstein-Barr virus infection is not a necessary condition of Non-Hodgkin Lymphoma. 
In other words, a human being can suffer from Non-Hodgkin Lymphoma even if not Epstein-Barr virus positive.

Proof.
The study of Teras et al. investigated the potential role of EBV in non-Hodgkin lymphomas (NHLs). The data as obtained by Teras et al. (Teras et al., 2015) are view by table 11.

Table 11.

The study of Teras et al. , 2015.

\begin{tabular}{|c|c|c|c|c|}
\hline $\begin{array}{l}\text { Country: } \\
\text { USA }\end{array}$ & & Non-Hodgkin & $\mathrm{NO}$ & \\
\hline \multirow{3}{*}{ EBV } & YES & 212 & 416 & 628 \\
\hline & NO & 13 & 33 & 46 \\
\hline & & 225 & 449 & 674 \\
\hline
\end{tabular}

\begin{tabular}{|c|c|c|c|c|c|}
\hline Causal relationship $\mathrm{k}=$ & $+0,029$ & $95 \% \mathrm{CI}(\mathrm{k}):$ & $-0,057$ & to & 0,116 \\
\hline$P$ value $(k \mid H G D)=$ & 0,27746 & Chi Sq. $(\mathrm{k})=$ & 0,582 & & \\
\hline$p(I O I)=$ & $\mathbf{0 , 5 9 8}$ & $p(\mathbf{I O U})=$ & 0,266 & $p(I O U)+p(I O I)=$ & $\mathbf{0 , 8 6 4}$ \\
\hline$p($ SINE $)=$ & 0,981 & $\mathrm{X}^{2}(\mathrm{SINE} \mid \mathrm{Bt})=$ & 0,751 & $\mathrm{X}^{2}(\mathbf{S I N E} \mid \underline{\mathbf{A}} \mathrm{t})=$ & 3,674 \\
\hline P likely $($ SINE $)=$ & 0,981 & $\mathrm{P}$ Value (SINE) $=$ & 0,019 & & \\
\hline p $($ IMP $)=$ & $\mathbf{0 , 3 8 3}$ & $\left.X^{2}(\mathrm{IMP} \mid \mathrm{At})\right)=$ & 275,567 & $\mathrm{X}^{2}(\mathrm{IMP} \mid \underline{\mathrm{B}} \mathrm{t})=$ & 385,425 \\
\hline $\mathrm{P}$ likely $(\mathrm{IMP})=$ & 0,539 & $\mathrm{P}$ Value $(\mathrm{IMP})=$ & 0,461 & & \\
\hline $\mathbf{p}\left(\mathrm{SINE}^{\wedge} \mathrm{IMP}\right)=$ & 0,364 & $\mathrm{X}^{2}\left(\mathrm{SINE}^{\wedge} \mathrm{IMP} \mid \mathrm{At}\right)=$ & 386,177 & $\mathrm{X}^{2}\left(\mathrm{SINE}^{\wedge} \mathrm{IMP} \mid \mathrm{Bt}\right)=$ & 386,177 \\
\hline $\mathrm{p}$ likely $\left(\mathrm{SINE}^{\wedge} \mathrm{IMP}\right)=$ & 0,529 & $\mathrm{p}$ Value $\left(\mathrm{SINE}^{\wedge} \mathrm{IMP}\right)=$ & 0,471 & & \\
\hline $\mathbf{p}(\mathbf{E X C L})=$ & 0,685 & $X^{2}(\mathrm{EXCL} \mid \mathrm{At})=$ & 71,567 & $\mathrm{X}^{2}(\mathrm{EXCL} \mid \mathrm{Bt})=$ & 199,751 \\
\hline $\mathrm{P}($ Likely EXCL $)=$ & 0,730 & $P$ Value $(E X C L)=$ & 0,270 & & \\
\hline Odds ratio $(\mathrm{OR})=$ & 1,294 & $95 \% \mathrm{CI}(\mathrm{OR}):$ & 0,667 & to & 2,510 \\
\hline
\end{tabular}

The index of independence of the study of Teras et al. ${ }^{58}$ is $\mathrm{p}(\mathrm{IOI})$ $=0,598$. The data are only of restricted value to consider the same data for the re-analysis of causal relationships or for the re-analysis of the exclusion relationship. The index of unfairness of this study is $\mathrm{p}(\mathrm{IOU})=0,266$ and allows to some extent to analyze the data for conditions or risk factors. The relative frequency of the conditio sine qua non relationship between Epstein-Bar virus (EBV) and NHL is $p($ SINE) $=0,980712$. The approximate $\mathrm{P}$ Value can be calculated as $\mathrm{P}$ Value $(\mathrm{SINE})=$ 0,019103 , a significant result. In the same respect, the causal relationship is positive but not significant. In other words, according to the data as provided by the study of Teras et al. ${ }^{58}$
EBV is a necessary condition of NHL or without EBV infection no NHL. The significance of these data tested by the Chi-square goodness of fit test (sample size $n=674$ ) yields the following results while the $X^{2}$ critical (degrees of freedom $=1$, Alpha 0,05) is $\mathrm{X}^{2}$ (critical) $=3,84145882$. Firstly. The data demand that the calculated $\mathrm{X}^{2}(\mathrm{SINE} \mid \mathrm{Bt})$ is $\mathrm{X}^{2}(\mathrm{SINE} \mid \mathrm{Bt})=(((13) *(13)) / 225)+0=$ 0,751 , a significant result. Secondly. The same data demand too that the calculated $\mathrm{X}^{2}(\mathrm{SINE} \mid \mathrm{Not} \mathrm{At})$ is $\mathrm{X}^{2}(\mathrm{SINE} \mid \mathrm{Not}$ At $)=$ $\left(\left((13)^{*}(13)\right) / 46\right)+0=3,674$, a significant result too. The data of the study of Teras et al.do support the hypothesis that $\mathbf{E B V}$ is a necessary condition of NHL while the causal relationship $k$ is positive, but not significant. Again, without an EBV infection CODEN (USA): JDDTAO 
no NHL. Mathematically a positive causal relationship, even if not significant, does not contradict the hypothesis of a conditio sine qua non relationship. The causal relationship $\mathrm{k}$ is $\mathrm{k}=0,029$ and positive while the approximate $95 \%$ coincidence interval of the causal relationship $\mathrm{k}$ is between $-0,057$ and 0,116 . The one-sided right tailed $\mathrm{P}$ Value of the causal relationship $\mathrm{k}$ calculated according to the hypergeometric distribution is $\mathrm{P}$ Value $(\mathrm{k} \mid \mathrm{HGD})=0,27746$ and not significant. In other words, according to the data of Teras et al. (Teras et al., 2015) we cannot reject the null-hypothesis: EBV is a necessary condition of Non-Hodgkin Lymphoma. There is another aspect to the characterization of this relationship: without an EBV infection no Non-Hodgkin Lymphoma.

\section{Quod erat demonstrandum.}

\section{DISCUSSION}

NHL consists of more than 40 major subtypes and is a very heterogeneous group of malignant lymphoid tumors. Historically, people suffered from NHL before the existence or the use of GS. In other words, historically, there is justified reason to believe that the existence or the use of GS is not a necessary condition for the development of NHL. Independently of this historical fact, todays data provide some evidence for this hypothesis too. The National Cancer Institute (NCI) reported 2019 about 19,6 new cases of non-Hodgkin lymphoma per 100,000 men and women per year ${ }^{59}$. The data as reported by NCI are viewed by the table (Table 12) below.

Table 12. Percent of New U. S. Cases of Non-Hodgkin Lymphoma by Age Group according to National Cancer Institute 2019 (NCI, 2019).

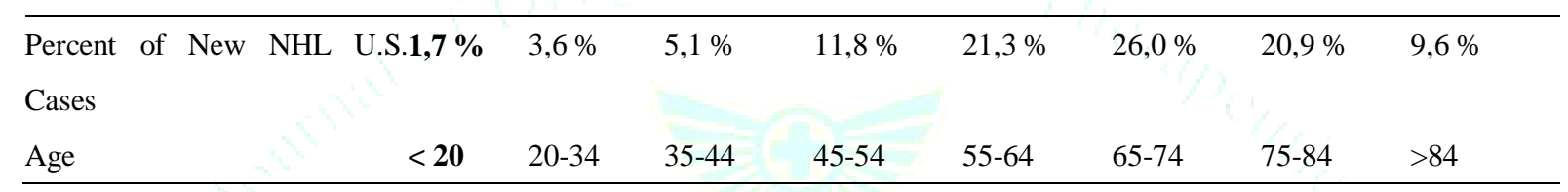

According to National Cancer Institute, NHL can occur at any age and especially in the childhood ${ }^{60}$. There does not appear to be any justifiable reason to assume, that very small children or even newborn children are working somehow with Glyphosate frequently or at all. Therefore, no human reason can provide serious evidence of the hypothesis that without GS no NHL. Glyphosate [N-(phosphonomethyl)glycine] has not been and is not a necessary condition for the development of Non-Hodgkin Lymphoma. None of the studies analyzed provided clear evidence of a significant conditio sine qua non relationship (without GS no NHL) between GS and NHL. Two studies (De Roos et al., 2005; Andreotti et al., 2018) were self-contradictory (Table 13) on this point.

Table 13. Overview of the results achieved.

\begin{tabular}{lcccccccccccc}
\hline Study ID & Year & \multicolumn{1}{c}{$\mathrm{N}$} & \multicolumn{1}{c}{ Case_P Case_T } & Con_P & Con_T & IOU & $\mathrm{k}$ & $\mathrm{X}^{2}\left(\mathrm{IMP} \mid \mathrm{A}_{\mathrm{t}}\right)$ & $\mathrm{X}^{2}\left(\mathrm{IMP} \mid \underline{\mathrm{B}}_{t}\right)$ & $\mathrm{X}^{2}\left(\operatorname{SINE} \mid \mathrm{B}_{\mathrm{t}}\right)$ & $\mathrm{X}^{2}\left(\operatorname{SINE} \mid \underline{\mathrm{A}}_{t}\right)$ \\
\hline McDuffie et al. & 2001 & 2023 & 51 & 517 & 133 & 1506 & $-0,65$ & $\mathbf{+ 0 , 0 2}$ & $\mathbf{9 6 , 1 4}$ & $\mathbf{1 1 , 7 5}$ & $\mathbf{4 2 0 , 0 3}$ & $\mathbf{1 1 8 , 0 8}$ \\
Hardell et al. & 2002 & 1656 & 8 & 515 & 8 & 1141 & $-0,68$ & $+0,04$ & $\mathbf{4 , 0 0}$ & $\mathbf{0 , 0 6}$ & 99,12 & 156,74 \\
De Roos et al. & 2003 & 2583 & 36 & 650 & 61 & 1933 & $-0,71$ & $\mathbf{+ 0 , 0 5}$ & $\mathbf{3 8 , 3 6}$ & $\mathbf{1 , 9 2}$ & 579,99 & 151,65 \\
De Roos et al. & 2005 & 54315 & 71 & 92 & 40964 & 54223 & $-0,24$ & $+0,00$ & 40893,12 & 30947,19 & 4,79 & 0,03 \\
Eriksson et al. & 2008 & 1926 & 29 & 910 & 18 & 1016 & $-0,50$ & $+\mathbf{0 , 0 5}$ & $\mathbf{6 , 8 9}$ & $\mathbf{0 , 3 2}$ & 852,92 & 413,07 \\
Orsi et al. & 2009 & 680 & 12 & 244 & 24 & 436 & $-0,59$ & $-0,01$ & $\mathbf{1 6 , 0 0}$ & $\mathbf{1 , 3 2}$ & 220,59 & 83,58 \\
Andreotti et al. & 2018 & 54251 & 440 & 575 & 43952 & 53676 & $-0,17$ & $\mathbf{- 0 , 0 1}$ & 43516,36 & 35989,61 & 31,70 & 1,85 \\
\hline
\end{tabular}

$\mathrm{N}=$ sample size. Case_P: case, positive. Case_T: number of cases. Con_P: control, positive, Con_T: number of controls. 


\section{Ilija Barukčić}

The only study which can be considered for a reanalysis is the study of McDuffie et al., 2001 with a $p(I O I)=0,165$ while none of the other studies analyzed provided non-self-contradictory data on the relationship between GS and NHL. Thus far, according to the data of the study of McDuffie et al., 2001, Glyphosate is neither a cause nor the cause of Non Hodgkin Lymphoma. The systematic review and meta-analysis by Chang and Delzell ${ }^{61}$ examined the relationship between Glyphosate exposure and among other, the risk of NHL and was not able to establish a causal relationship between Glyphosate exposure and the risk of any type of lymphohematopoietic cancer (LHC) including NHL. In contrast to Chang and Delzell, the meta-analysis conducted by Zang et al. ${ }^{62}$ used published human studies on the relationship between exposures to GS and NHL and reported that GS exposure is associated with increased risk of NHL. However, the meta-analysis of Zang et al. is grossly flawed, one-sided and worthless in toto due to several reasons. The data of the most studies considered by Zang et al. (Zhang, Rana, Taioli, Shaffer, \& Sheppard, 2019) are self-contradictory and of none or of an extremely limited value, which was ignored by the study group completely. Other possible factors which are causally related to NHL were not considered at all or even to a necessary extent. Statistical methods, far away from being able, to provide anything valuable on the point of issue, were used with the consequence that everything desirable can be proofed as correct, even pure non-sense. The inconsistency of Forest plot ${ }^{46}$ supported meta-analysis was ignored completely. The results of this systematic review and meta-analysis suggest that EBV and not Glyphosate is causally linked with a wider spectrum of NHL subtypes. Still, this cannot be considered as the final proof of the relationship between EBV and NHL and further and better designed studies are needed to confirm and fully understand the etiology of NHL. Besides of all, as long as no better data are available, it is justified, necessary and allowed to deduce the following conclusion.

\section{CONCLUSION}

Glyphosate is neither a cause nor the cause of Non-Hodgkin Lymphoma.

\section{Acknowledgements}

The open source, independent and non-profit Zotero Citation Manager was used to create and manage references and
Journal of Drug Delivery \& Therapeutics. 2020; 10(1-s):6-29

bibliographies. The public domain software GnuPlot is used frequently, to draw some figures.

\section{Author Contributions}

The author confirms being the sole contributor of this work and has approved it for publication.

\section{Conflict of Interest Statement}

The author declares that the research was conducted in the absence of any commercial or financial relationships that could be construed as a potential conflict of interest. There are no conflict of interest exists according to the guidelines of the International Committee of Medical Journal Editors.

\section{Financial support and sponsorship}

Nil.

\section{REFERENCES}

1. Malpighi M. De viscerum structura exercitatio anatomica.Accedit dissertatio eiusdem De polypo cordis, Bononiae: Iacobi Montij; 1666. doi https://doi.org/10.3931/e-rara-23974

2. Hodgkin T. On some Morbid Appearances of the Absorbent Glands and Spleen, Medico-Chir Trans, 1832; 17:68-114. https://www.ncbi.nlm.nih.gov/pmc/articles/PMC2116706/.

3. Wilks S. Cases with enlargement of the lymphatic glands and spleen (or Hodgkin's disease) with remarks, Guys Hosp Rep, 1865.

4. Armitage JO, Gascoyne RD, Lunning MA, Cavalli F. Non-Hodgkin lymphoma, Lancet Lond Engl, 2017; 390(10091):298-310. doi: https://doi.org/10.1016/S0140-6736(16)32407-2 [PMID: 28153383]

5. Virchow R. Weisses Blut. Neue Notizen aus dem Gebiet der Naturfund Heilkunde, Florieps Neue Not, 1845; 36:151

https://www.ncbi.nlm.nih.gov/pmc/articles/PMC2116706/.

6. Bennett JH. Two cases of disease and enlargement of thespleen in which death took place from the presence of purulentmatter in the blood, Edinb Med Surg J, 1845; 64:413-423. https://onlinelibrary.wiley.com/doi/pdf/10.1046/j.1365-2141.2000.01988 .x.

7. Cohnheim P. Ein Fall von Pseudoleukämie, Arch Für Pathol Anat Physiol Für Klin Med, 1865; 33(3):451-454. doi: https://doi.org/10.1007/BF02137492

8. Rappaport H. Tumors of the Hematopoietic System, Washington: Armed Forces Institute of Pathology; 1966. http://annals.org/article.aspx?doi=10.7326/0003-4819-67-3-686_2 Accessed May 15, 2019 
9. IARC WG on the E of CR to H. IARC Monographs on the Evaluation of Carcinogenic Risks to Humans. Volume 112, Vol 112. ; 2017.

10. EPA US. U.S. Environmental Protection Agency Reregistration Eligibility Decision (RED) Glyphosate, Environ Prot Agency Wash DCUS, 1993; EPA-738-R-93-014.

11. Williams GM, Kroes R, Munro IC. Safety evaluation and risk assessment of the herbicide Roundup and its active ingredient, glyphosate, for humans, Regul Toxicol Pharmacol RTP, 2000; 31(2 Pt 1):117-165. doi: https://doi.org/10.1006/rtph.1999.1371 [PMID: 10854122]

12. Steinrücken $\mathrm{HC}$, Amrhein $\mathrm{N}$. The herbicide glyphosate is a potent inhibitor of 5-enolpyruvyl-shikimic acid-3-phosphate synthase, Biochem Biophys Res Commun, 1980; 94(4):1207-1212. [PMID: 7396959]

13. Bolognesi C, Bonatti S, Degan P, et al. Genotoxic Activity of Glyphosate and Its Technical Formulation Roundup, J Agric Food Chem, 1997; 45(5):1957-1962. doi: https://doi.org/10.1021/jf9606518

14. Daruich J, Zirulnik F, Gimenez MS. Effect of the herbicide glyphosate on enzymatic activity in pregnant rats and their fetuses, Environ Res, 2001; 85(3):226-231. doi: https://doi.org/10.1006/enrs.2000.4229 [PMID: $11237511]$

15. El-Demerdash FM, Yousef MI, Elagamy EI. Influence of paraquat, glyphosate, and cadmium on the activity of some serum enzymes and protein electrophoretic behavior (in vitro), J Environ Sci Health B, 2001; 36(1):29-42. [PMID: 11281253]

16. Hietanen E, Linnainmaa K, Vainio $\mathrm{H}$. Effects of phenoxyherbicides and glyphosate on the hepatic and intestinal biotransformation activities in the rat, Acta Pharmacol Toxicol (Copenh), 1983; 53(2):103-112. [PMID: $6624478]$

17. Lioi MB, Scarfì MR, Santoro A, et al. Genotoxicity and oxidative stress induced by pesticide exposure in bovine lymphocyte cultures in vitro, Mutat Res, 1998; 403(1-2):13-20. [PMID: 9726001]

18. Olorunsogo OO, Bababunmi EA, Bassir O. Effect of glyphosate on rat liver mitochondria in vivo, Bull Environ Contam Toxicol, 1979;

\section{2(3):357-364. [PMID: 223703]}

19. Peluso M, Munnia A, Bolognesi C, Parodi S. 32P-postlabeling detection of DNA adducts in mice treated with the herbicide Roundup, Environ Mol Mutagen, 1998; 31(1):55-59. [PMID: 9464316]

20. Walsh LP, McCormick C, Martin C, Stocco DM. Roundup inhibits steroidogenesis by disrupting steroidogenic acute regulatory (StAR) protein expression, Environ Health Perspect, 2000; 108(8):769-776. doi: https://doi.org/10.1289/ehp.00108769 [PMID: 10964798] [PMCID: PMC1638308]

21. Yousef MI, Salem MH, Ibrahim HZ, Helmi S, Seehy MA, Bertheussen K Toxic effects of carbofuran and glyphosate on semen characteristics in rabbits, J Environ Sci Health B, 1995; 30(4):513-534. doi https://doi.org/10.1080/03601239509372951 [PMID: 7797819]
Journal of Drug Delivery \& Therapeutics. 2020; 10(1-s):6-29

22. Pearson K. On the Theory of Contingency and Its Relation to Association and Normal Correlation, London: Dulau and Co.; 1904.

23. Fisher RA. On the Interpretation of $\chi 2$ from Contingency Tables, and the Calculation of P, J R Stat Soc, 1922; 85(1):87. doi: https://doi.org/10.2307/2340521

24. Bortz J, Lienert GA, Boehnke K. Verteilungsfreie Methoden in der Biostatistik: mit 247 Tabellen, Berlin: Springer; 1990.

25. Scheid H. Wahrscheinlichkeitsrechnung, Vol 6. Mannheim: BI-Wiss.-Verl.; 1992

26. Liberati A, Altman DG, Tetzlaff J, et al. The PRISMA statement for reporting systematic reviews and meta-analyses of studies that evaluate health care interventions: explanation and elaboration, PLoS Med, 2009; 6(7):1000100. doi: https://doi.org/10.1371/journal.pmed.1000100 [PMID: 19621070]

27. Moher D, Liberati A, Tetzlaff J, Altman DG. Preferred reporting items for systematic reviews and meta-analyses: the PRISMA Statement, Open Med Peer-Rev Indep Open-Access J, 2009; 3(3):123-130. [PMID: 21603045]

28. Hardell L, Eriksson M. A case-control study of non-Hodgkin lymphoma and exposure to pesticides, Cancer, 1999; 85(6):1353-1360. [PMID: 10189142]

29. Leon ME, Schinasi LH, Lebailly P, et al. Pesticide use and risk of non-Hodgkin lymphoid malignancies in agricultural cohorts from France, Norway and the USA: a pooled analysis from the AGRICOH consortium, Int J Epidemiol, 18 2019. doi: https://doi.org/10.1093/ije/dyz017 [PMID: 30880337]

30. Barukčić I. Die Kausalität, 1. Aufl. Hamburg: Wiss.-Verl.; 1989.

31. Barukčić I. Die Kausalität, 2., völlig überarb. Aufl. Wilhelmshaven: Scientia; 1997.

32. Barukčić I. The Mathematical Formula of the Causal Relationship k, Int J Appl Phys Math, 2016; 6(2):45-65. doi: https://doi.org/10.17706/ijapm.2016.6.2.45-65

33. Barukčić I. Unified Field Theory, J Appl Math Phys, 2016; 04(08):1379-1438. doi: https://doi.org/10.4236/jamp.2016.48147

34. Barukčić I. Die Kausalität, Reprint of first Edition 1989. Norderstedt: Books on Demand; 2017

35. Barukčić I. Epstein-barr virus is the cause of multiple sclerosis, Int J Curr Med Pharm Res, 2018; 4(9 (A)):3674-3682. doi: https://doi.org/10.24327/23956429.ijcmpr20180538

36. Barukčić I. Smoking of tobacco is the cause of human lung cancer, J Drug Deliv Ther, 2019; 9(1-s):148-160. doi https://doi.org/10.22270/jddt.v9i1-s.2273

37. Barukčić K, Barukčić I. Epstein Barr Virus-The Cause of Multiple Sclerosis, J Appl Math Phys, 2016; 04(06):1042-1053. doi: https://doi.org/10.4236/jamp.2016.46109 


\section{Ilija Barukčić}

38. Hessen J. Das Kausalprinzip, Augsburg: Filser; 1928.

39. Korch H. Das Problem Der Kausalität, Berlin: Dt. Verlag der Wissenschaften; 1965

40. Barukčić I. Helicobacter Pylori is the Cause of Gastric Cancer, Mod Health Sci, 2018; 1(1):43-50. doi: https://doi.org/10.30560/mhs.v1n1p43

41. Barukčić K, Barukčić JP, Barukčić I. Epstein-Barr virus is the cause of rheumatoid arthritis, Romanian J Rheumatol, 2018; 27(4):148-163. https://view.publitas.com/amph/rjr_2018_4_art-02/page/1. Accessed December 29, 2018.

42. Uspensky J v. Introduction To Mathematical Probability, New York (USA): McGraw-Hill Company; 1937.

43. Pearson K. X. On the criterion that a given system of deviations from the probable in the case of a correlated system of variables is such that it can be reasonably supposed to have arisen from random sampling, Lond Edinb Dublin Philos Mag J Sci, 1900; 50(302):157-175.

44. Barukčić I. Human Papillomavirus - The Cause of Human Cervical Cancer, J Biosci Med, 2018; 06(04):106-125. doi: https://doi.org/10.4236/jbm.2018.64009

45. Barukčić I. Statins and death due to any cause - all doubts removed?, Int J Curr Sci Res, 2019; 5(12):1884-1911.

46. Barukčić I. Index of Unfairness, Mod Health Sci, 2019; 2(1):p22. doi: https://doi.org/10.30560/mhs.v2n1p22

47. Barukčić I. Index of Independence, Mod Health Sci, 2019; 2(2):1-25. doi: https://doi.org/10.30560/mhs.v2n2p1

48. McDuffie HH, Pahwa P, McLaughlin JR, et al. Non-Hodgkin's lymphoma and specific pesticide exposures in men: cross-Canada study of pesticides and health, Cancer Epidemiol Biomark Prev Publ Am Assoc Cancer Res Cosponsored Am Soc Prev Oncol, 2001; 10(11):1155-1163. [PMID: 11700263]

49. Barukčić I. The P Value of likely extreme events, Int J Curr Sci Res, 2019; 5(11):1841-1861

http://www.drbgrpublications.in/ijcsr-179-The-P-Value-of-likely-extrem e-events-Ilija-Baruk\%C4\%8Di\%C4\%87.pdf.

50. Hardell L, Eriksson M, Nordstrom M. Exposure to pesticides as risk factor for non-Hodgkin's lymphoma and hairy cell leukemia: pooled analysis of two Swedish case-control studies, Leuk Lymphoma, 2002;

43(5):1043-1049. [PMID: 12148884]

51. De Roos AJ, Zahm SH, Cantor KP, et al. Integrative assessment of multiple pesticides as risk factors for non-Hodgkin's lymphoma among men, Occup Environ Med, 2003; 60(9):E11. doi https://doi.org/10.1136/oem.60.9.e11 [PMID: 12937207] [PMCID: PMC1740618]

52. Cantor KP. Farming and mortality from non-Hodgkin's lymphoma: a case-control study, Int J Cancer, 1982; 29(3):239-247. [PMID: 7040259]
Journal of Drug Delivery \& Therapeutics. 2020; 10(1-s):6-29

53. De Roos AJ, Blair A, Rusiecki JA, et al. Cancer incidence among glyphosate-exposed pesticide applicators in the Agricultural Health Study, Environ Health Perspect, 2005; 113(1):49-54. doi: https://doi.org/10.1289/ehp.7340 [PMID: 15626647] [PMCID PMC1253709]

54. Eriksson M, Hardell L, Carlberg M, Akerman M. Pesticide exposure as risk factor for non-Hodgkin lymphoma including histopathological subgroup analysis, Int J Cancer, 2008; 123(7):1657-1663. doi: https://doi.org/10.1002/ijc.23589 [PMID: 18623080]

55. Orsi L, Delabre L, Monnereau A, et al. Occupational exposure to pesticides and lymphoid neoplasms among men: results of a French case-control study, Occup Environ Med, 2009; 66(5):291-298. doi: https://doi.org/10.1136/oem.2008.040972 [PMID: 19017688] [PMCID PMC2728754]

56. Andreotti G, Koutros S, Hofmann JN, et al. Glyphosate Use and Cancer Incidence in the Agricultural Health Study, J Natl Cancer Inst, 2018; 110(5):509-516. doi: https://doi.org/10.1093/jnci/djx233 [PMID: 29136183] [PMCID: PMC6279255]

57. IARC WG on the $\mathrm{E}$ of $\mathrm{CR}$ to H. Biological agents. Volume $100 \mathrm{~B}$. A review of human carcinogens., Iarc Monogr Eval Carcinog Risks Hum, 2012; 100(PT B):1-441.

https://www.ncbi.nlm.nih.gov/pmc/articles/PMC4781184/. Accessed May 19, 2019. [PMID: 23189750] [PMCID: PMC4781184]

58. Teras LR, Rollison DE, Pawlita M, et al. Epstein-Barr virus and risk of non-Hodgkin lymphoma in the cancer prevention study-II and a meta-analysis of serologic studies, Int J Cancer, 2015; 136(1):108-116. doi: https://doi.org/10.1002/ijc.28971 [PMID: 24831943]

59. National Cancer Institute NI of H. Non-Hodgkin Lymphoma - Cancer Stat Facts, Natl Cancer Inst - Surveill Epidemiloogy End Results Program, 2019; May 18. https://seer.cancer.gov/statfacts/html/nhl.html. Accessed May 18, 2019.

60. Sandlund JT. Non-Hodgkin Lymphoma in Children, Curr Hematol Malig Rep, 2015; 10(3):237-243. doi: https://doi.org/10.1007/s11899-015-0277-y [PMID: 26174528]

61. Chang ET, Delzell E. Systematic review and meta-analysis of glyphosate exposure and risk of lymphohematopoietic cancers, J Environ Sci Health B, 2016; 51(6):402-434. doi: https://doi.org/10.1080/03601234.2016.1142748 [PMID: 27015139] [PMCID: PMC4866614]

62. Zhang L, Rana I, Taioli E, Shaffer R, Sheppard L. Exposure to Glyphosate-Based Herbicides and Risk for Non-Hodgkin Lymphoma: A Meta-Analysis and Supporting Evidence, Mutat Res Mutat Res, February 2019. doi: https://doi.org/10.1016/j.mrrev.2019.02.001 